\title{
Hydrogen bonding in amorphous calcium carbonate and molecular reorientation induced by dehydration
}

\author{
Anders C. S. Jensen, Silvia Imberti, Stewart F. Parker, \\ Emanuel Schneck, Yael Politi, Peter Fratzl, Luca Bertinetti, \\ and Wouter J. E. M. Habraken
}

\begin{abstract}
Published version information
Citation: ACS Jensen et al. "Hydrogen bonding in amorphous calcium carbonate and molecular reorientation induced by dehydration." Journal of Physical Chemistry C, vol. 122 , no. 6 (2018): 3591-3598.
\end{abstract}

DOI: $10.1021 / a c s . j p c c .7 b 10459$

This document is the unedited author's version of a Submitted Work that was subsequently accepted for publication in Journal of Physical Chemistry C, (C) 2018 American Chemical Society, after peer review. To access the final edited and published work see DOI above.

Please cite only the published version using the reference above. This is the citation assigned by the publisher at the time of issuing the AAM. Please check the publisher's website for any updates. 


\title{
Hydrogen Bonding in Amorphous Calcium Carbonate and Molecular Reorientation Induced by Dehydration
}

Anders C. S. Jensen ${ }^{\mathrm{a}}$, Silvia Imberti ${ }^{\mathrm{b}}$, Stewart F. Parker ${ }^{\mathrm{b}}$, Emanuel Schneck ${ }^{\mathrm{a}}$, Yael Politi ${ }^{\mathrm{a}}$, Peter Fratzl $^{a}$, Luca Bertinetti*a and Wouter J.E.M. Habraken ${ }^{a}$

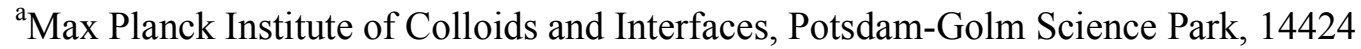

Potsdam, Germany and ${ }^{\mathrm{b}}$ STFC, Rutherford Appleton Laboratory, ISIS Pulsed Neutron and Muon Source, Didcot, OX11 0QX, UK

*corresponding author: Email: luca.bertinetti@mpikg.mpg.de

\begin{abstract}
Amorphous calcium carbonate (ACC) is a meta-stable hydrated solid that has received great attention as a precursor in calcium carbonate crystallization in both synthetic and biological systems. In particular, the atomic structure of ACC is a matter of ongoing discussion. Some studies have pointed out similarities between the local structure of amorphous calcium carbonate and its crystalline counterparts, whereas others suggested no resemblance to any known crystalline form. Despite the large number of studies, few structural aspects have been described beyond the first $\mathrm{Ca}-\mathrm{O}$ distance and coordination number. Specifically, the role of carbonate ions and water molecules in the amorphous network are poorly understood. Here we address this issue using neutron and x-ray total scattering in combination with molecular modeling on a set of well-defined synthetic $\mathrm{CaCO}_{3} \cdot n \mathrm{H}_{2} \mathrm{O}$ samples, synthesized by rapid mixing of $\mathrm{CaCl}_{2}$ and $\mathrm{Na}_{2} \mathrm{CO}_{3}$ solutions and with two levels of hydration, $n=1.1$ and $n=0.5$. An atomistic model of ACC is derived based on the total scattering data and the results were substantiated by spectroscopic techniques, with particular focus on the hydrogen bonding. Our results show that the ACC studied here has a broad distribution of coordination numbers for all coordination spheres. A close structural relationship is found between water and carbonate, whereby the loss of water induces a rearrangement of the carbonate ions with negligible change in total number of oxygen atoms coordinated with the calcium ion. We find that the local environments of the ions in ACC are more similar to those of ions in solution than to any of the crystalline forms of calcium carbonate.
\end{abstract}

\section{Introduction:}

Amorphous precursors play a key role in mineral formation. In both biological and synthetic settings, they are either exploited for their unique properties, which are clearly distinct from their crystalline counterparts ${ }^{1-4}$ or stored and crystallized when needed ${ }^{3-6}$. ACC in particular, is of special interest due to its widespread occurrence in biology, where it is found in two forms; a transient and a stabilized form ${ }^{3-4,7}$. Transient biogenic ACCs act as precursors for crystalline biominerals and have proven difficult to study due to their short-lived nature ${ }^{3,8}$. Transient ACCs have been shown to exhibit different local structures ${ }^{3}$. Moreover, they were generally found to dehydrate prior to crystallization ${ }^{9-10}$ suggesting that dehydration may play a key role in destabilizing $\mathrm{ACC}^{11}$. Stabilized biogenic $\mathrm{ACC}$, is often hydrated with $n=N_{\mathrm{H} 2 \mathrm{O}} / N_{\mathrm{Ca}} \approx 1^{12}$, crystallization is prevented by the presence of various additives. This type 
of ACC is long-lived and have been found to be structurally very similar to synthetic ACC ${ }^{13}$, despite showing organism-specific short range order. ${ }^{12}$.

Several structural models have been suggested for synthetic ACC based on diffraction techniques, but these have either poorly reproduced the experimental diffraction pattern ${ }^{14-15}$ or have only relied on x-ray total scattering, which is mostly sensitive to calcium but much less to the lighter elements in ACC ${ }^{16}$. Earlier molecular dynamics (MD) simulation studies by Bushuev et al. ${ }^{17}$ and Malini et al. ${ }^{18}$, which were focused on structural changes related to a range of hydration levels $(0 \leq n \leq 6)$, predicted a percolation threshold at high hydration levels $(n>0.9)$ where water pores are formed. However, they found no evidence of large scale separation of $\mathrm{Ca}^{2+}$ and $\mathrm{CO}_{3}{ }^{2-}$ as suggested by Goodwin et $\mathrm{al}^{16}$. The local environment of water has also been extensively studied with NMR on both biogenic ${ }^{13,19-20}$ and synthetic ACC $^{11,21-}$ 25 . These studies reported both translationally restricted and mobile water as well as hydroxide ions in $\mathrm{ACC}{ }^{11,23,25}$. However, the amount of hydroxides is highly dependent on the initial $\mathrm{pH}$ during formation ${ }^{26}$ and the concentration of hydroxides is negligible in the samples analyzed in the present study.

Here, we present an atomistic model of ACC derived from empirical potential structural refinement (EPSR) ${ }^{27-29}$ based on simultaneous fitting of $\mathrm{x}$-ray and neutron total scattering data. Since accurate knowledge of the ACC composition is essential for EPSR analysis, we used a previously established procedure ${ }^{30}$ for the reproducible generation of ACC with a hydration level of $n=1.1 \pm 0.03$. A sample with $n=0.5$ was also prepared to probe the structure below the expected percolation threshold ${ }^{17}$. Vibrational spectroscopy was used to support the findings of the EPSR model. In good agreement with theoretical work ${ }^{17-18}$, we find that the two samples with hydration levels $n=1.1$ and $n=0.5$ reside above and below the percolation threshold, respectively, as predicted by Bushuev et al. ${ }^{17}$. The average coordination number of $\mathrm{Ca}$ is similar to that reported by Malini et al. for $\mathrm{CaCO}_{3} \cdot \mathrm{H}_{2} \mathrm{O}^{18}$ although the density therein reported was found to be somewhat higher than our experimental values. Unlike previous studies, we find that the local order is closely related to that of the hydrated ions in solution prior to precipitation and less to that of the final crystalline product as had been previously suggested ${ }^{31}$.

\section{Results:}

The ACC as prepared had the composition $\mathrm{CaCO}_{3} \cdot n \mathrm{H}_{2} \mathrm{O}$ with $n=1.1$ and a partially dehydrated sample with $n=0.5$ was prepared by heat treatment. The composition was determined by thermogravimetric analysis (TGA) (figure $\mathrm{S} 1$, see supporting information). The mass densities of 2.282(2) and 2.428(2) $\mathrm{g} / \mathrm{cm}^{3}$ for the samples with $n=1.1$ and $n=0.5$, respectively, were determined with an Ar-gas pycnometer and reveal a densification during dehydration. The neutron and x-ray structure factors and pair distribution functions (pdfs) of both samples are shown in figure 1. All correlations in the pdfs below $2.3 \AA$ originate from the intramolecular distances in the carbonate ion and water. The first intermolecular correlation peak corresponds to the $\mathrm{Ca}-\mathrm{O}$ bond at $2.4 \AA$. The high intensities of the peaks at 4 $\AA$ and $6 \AA$ in the X-ray pdfs compared to the neutron pdfs can be attributed to the Ca-Ca correlations, to which the X-ray measurements are particularly sensitive. A full deconvolution 
of the pdfs into the individual partial pair distribution functions (ppdfs or $\mathrm{g}_{\alpha \beta}(\mathrm{r})$ ) was achieved through the EPSR modeling (figure 2, 3 and S2).

EPSR model fitting: The EPSR model was setup as described in the Materials and methods section. In brief, a cubic box with $2.6 \mathrm{~nm}$ side length, large enough to avoid finite size effects, was filled with atoms to reproduce the composition and density determined for the samples. The model was then energy minimized via a Monte Carlo simulation. The energy minimized models structure factors are compared to the experimental data and refined via addition of empirical potentials until optimal agreement is achieved. To gain sufficient statistics in order to accurately describe the structure of ACC, an ensemble of at least 10000 configurations obtained with the refined potentials was averaged. The final fit is shown in figure 1, where all the main features are reproduced in both the structure factors $(S(Q)$, figure $1 \mathrm{~A})$ and in the pdfs (figure 1B). A mismatch at very low $Q$ (figure 1a bottom) in the neutron $S(Q)$ is caused by the high sensitivity to the inelastic scattering correction in this range.

The obtained EPSR model shows no large scale separation of molecular species (vide infra) as previously suggested ${ }^{16}$. The model also shows that the mean coordination number $(\mathrm{CN})$ of all coordination spheres increases upon dehydration, except for those coordination spheres that include water (table S3). For all coordination spheres a broad distribution of CN was found as expected for an amorphous system. The most interesting feature of our model and the focus of this study is the effect of dehydration on carbonate ion and the hydrogen bonding in ACC.
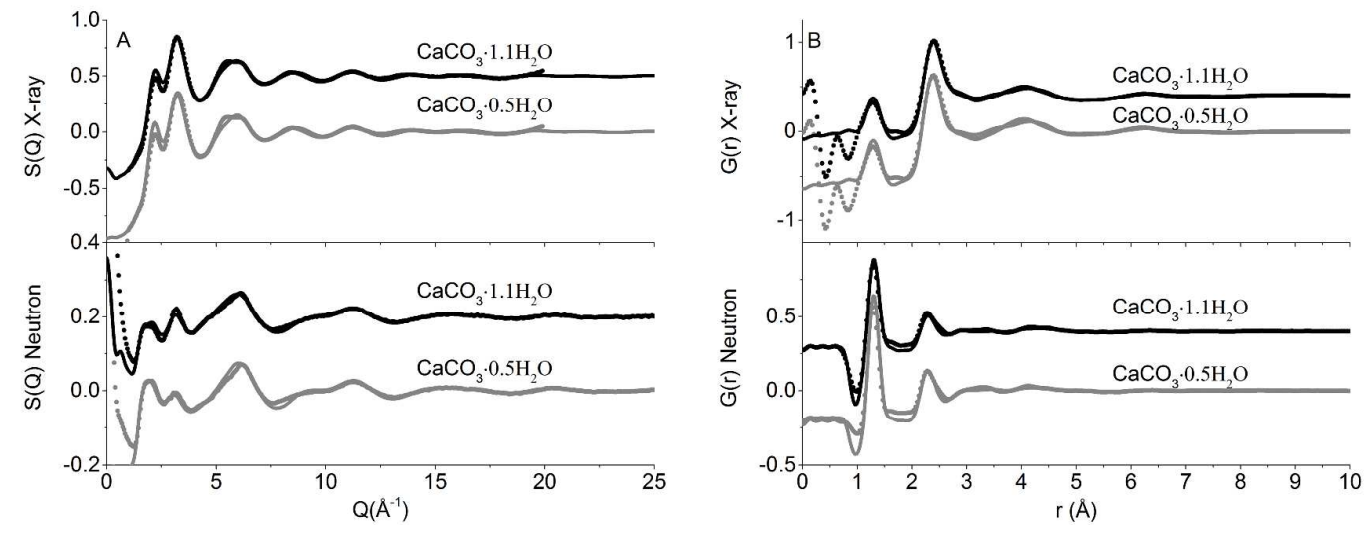

Figure 1. Experimental (dots) and simulated (lines) structure factor as a function of the scattering vector Q (A) and pdf (B) of ACC for both hydration levels. Data measured with Xrays above and neutrons below. The peaks $<1 \AA$ in the x-ray pdf are caused by truncation errors and noise in the data and do not represent physical interatomic distances.

Calcium environment: In figure 2A and 2B the partial pair correlations related to calcium for both samples are shown. The longest distance correlation is found in the calcium/calcium ppdf, $\mathrm{g}_{\mathrm{CaCa}}(\mathrm{r})$, with two broad coordination shells at $\sim 4 \AA$ and $\sim 6.2 \AA$ (figure $2 \mathrm{~A}$ ), similar to that found in all the crystalline compounds except ikaite ${ }^{32}$ (in which the coordination sphere at $\sim 4 \AA$ is lacking). The calcium/carbonate-oxygen ppdf, $\mathrm{g}_{\mathrm{CaOc}}(\mathrm{r})$, shows two coordination spheres centered at $2.37 \AA$ and $4.11 \AA$ (figure $2 \mathrm{~A}$ ). Similar distances are found in all the crystalline compounds for $\mathrm{Ca}_{-} \mathrm{O}_{\mathrm{c}}$ distances. In the calcium/carbon ppdf, $\mathrm{g}_{\mathrm{CaC}}(\mathrm{r})$, the radii of two closely spaced coordination shells are found at $2.85 \AA$ and $3.4 \AA$ (figure 2A), 
characteristic of bidentate and monodentate carbonate ions respectively ${ }^{32-36}$. The ratio between bidentate and monodentate was found to be 1.1/3.7 and 1.2/4.1 for $n=1.1$ and 0.5 respectively. The calcium/water-oxygen ppdf, $\mathrm{g}_{\mathrm{CaOw}}(\mathrm{r})$, shows one coordination sphere at 2.43 $\AA$ (figure $2 \mathrm{~B}$ ), slightly larger than the $\mathrm{Ca}-\mathrm{O}_{\mathrm{c}}$ distance as observed in both ikaite ${ }^{32}$ and monohydrocalcite (MHC) ${ }^{33}$. The calcium/water-hydrogen ppdf, $\mathrm{g}_{\mathrm{CaHw}}(\mathrm{r})$, shows a single broad coordination sphere at $2.9 \AA$ (figure $2 \mathrm{~B}$ ). The model showed that $10 \%$ and $2.7 \%$ of the water is not binding directly to the calcium ion for $n=1.1$ and $n=0.5$ respectively. However, all the water molecules were found to coordinate directly with oxygen on the carbonate ion for both hydration levels.

Only small changes are observed in the pair correlations relating to $\mathrm{Ca}$ upon dehydration. However, the differences between the samples become more apparent in the $\mathrm{CN}$ distribution for the first $\mathrm{Ca}-\mathrm{O}_{\mathrm{c}}$ and $\mathrm{Ca}-\mathrm{O}_{\mathrm{w}}$ coordination spheres (figure $2 \mathrm{C}$ ). From the $\mathrm{CN}$ distribution, we see $\mathrm{Ca}$ binds most frequently to one water molecule $(\mathrm{CN} \approx 1)$, but with a wide distribution so that the mean $\mathrm{CN}$ is 1.4 (table $\mathrm{S} 3$ ) for the sample with $n=1.1$. Upon dehydration, the majority of the $\mathrm{Ca}$ ions become anhydrous and the mean $\mathrm{CN}$ drops to 0.8 (table $\mathrm{S} 3$ ). For $\mathrm{O}_{\mathrm{c}}$ binding to $\mathrm{Ca}$ the $\mathrm{CN}$ distribution shows a corresponding increase upon dehydration going from a mean $\mathrm{CN}$ of 5.7 to 6.3 (table $\mathrm{S} 3$ ). Adding the $\mathrm{CN}$ of $\mathrm{O}_{\mathrm{w}}$ and $\mathrm{O}_{\mathrm{c}}$ around $\mathrm{Ca}$ gives a mean $\mathrm{CN}$ of $\mathrm{O}_{\mathrm{c}+\mathrm{w}}$ binding to $\mathrm{Ca}$ of 7.1 for both hydration levels. This constant mean $\mathrm{CN}$ of $\mathrm{O}_{\mathrm{c}+\mathrm{w}}$ binding around $\mathrm{Ca}$ at both hydration levels indicates that the removal of water molecules forces the carbonate ions to rearrange to coordinate more calcium ions. This results in a $\sim 10 \%$ increase in the number of $\mathrm{Ca}$ ions around each $\mathrm{O}_{\mathrm{c}}$ (table S3). The mean distances of both the $\mathrm{Ca}-\mathrm{O}_{\mathrm{c}}$ and $\mathrm{Ca}-$ $\mathrm{O}_{\mathrm{w}}$ in the first coordination sphere were calculated (figure $\mathrm{S} 3$ ) for each $\mathrm{CN}$ and, while $\mathrm{Ca}-\mathrm{O}_{\mathrm{c}}$ distances increase with $\mathrm{CN}, \mathrm{Ca}-\mathrm{O}_{\mathrm{w}}$ distances remain constant for all $\mathrm{CN}$. The O-Ca-O angle was examined using the angular distribution (figure S4). The angular distribution of $\mathrm{O}_{\mathrm{c}}$ around $\mathrm{Ca}$ (figure S4A) shows two peaks at low angles originating from nearest neighbor carbonate ions, but no preferred angles are found at high angle. In contrast, the angular distribution of $\mathrm{O}_{\mathrm{w}}$ around $\mathrm{Ca}$ shows two preferred angles at $65^{\circ}$ and $140^{\circ}$ (figure S4B), similar to that of $\mathrm{Ca}$ ions in solution ${ }^{37}$.
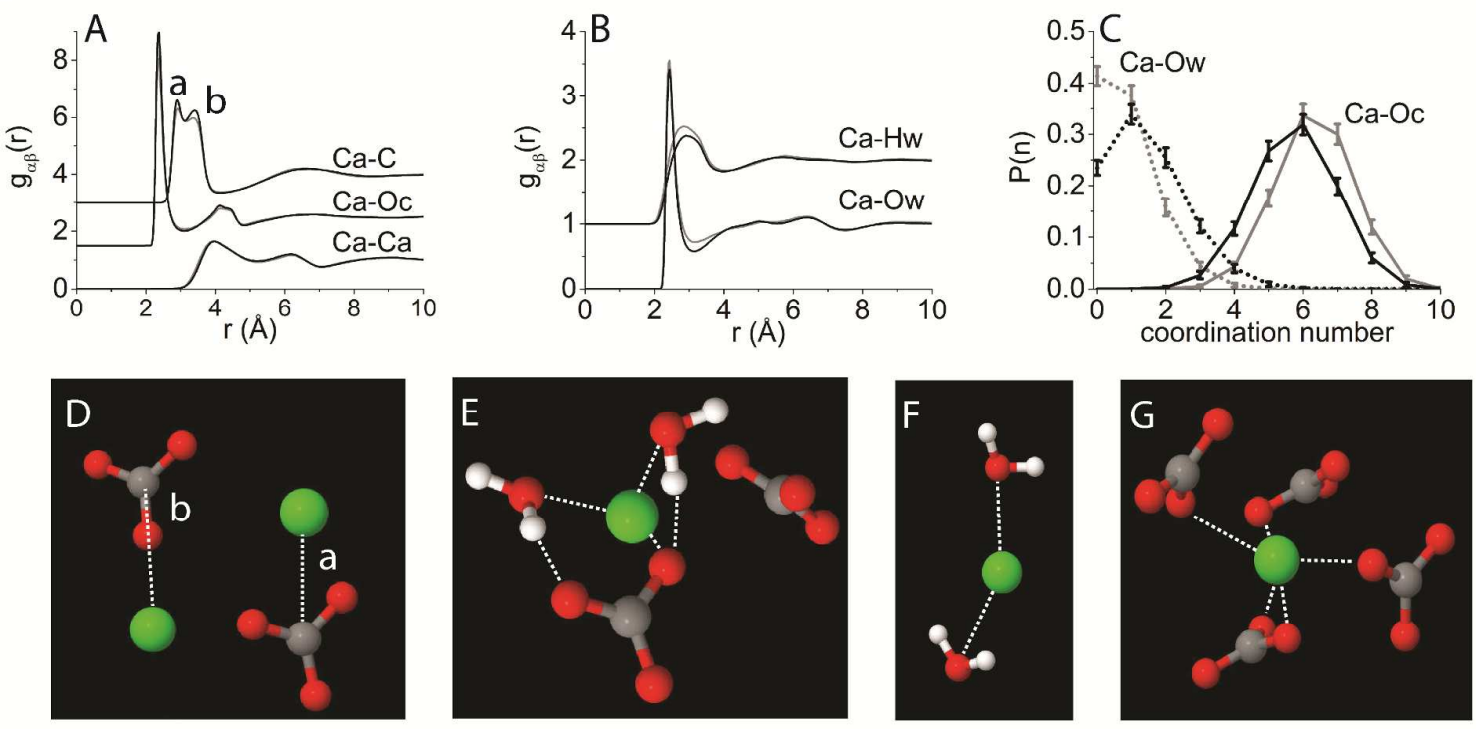
Figure 2. Selected inter-molecular ppdfs of Ca relating to $\mathrm{Ca}^{2+}$ and $\mathrm{CO}_{3}{ }^{2-}(\mathrm{A})$, related to water (B) and the distribution in coordination number of $\mathrm{O}$ around $\mathrm{Ca}$ in the first coordination sphere from $2 \AA$ to $3.2 \AA(\mathrm{C})$. Example of the coordination of carbonate binding to calcium with $\mathrm{Ca}-\mathrm{C}$ distances for bidentate (a) and monodentate (b) highlighted (D, water not shown). Example of the coordination of oxygen binding to calcium, both $\mathrm{Ca}-\mathrm{O}$ and $\mathrm{H}-\mathrm{O}$ bonds are marked; notice the hydrogen on water is oriented to form $\mathrm{H}$-bonds with the nearest carbonate (E, only atoms above $\mathrm{Ca}$ are shown). Example of $\mathrm{Ca}-\mathrm{O}_{\mathrm{w}}\left(\mathrm{F}\right.$, carbonates not shown) and $\mathrm{Ca}-\mathrm{O}_{\mathrm{c}}$ ( $\mathrm{G}$, water not shown) first coordination sphere. In A-C black lines and grey lines represent data from $n=1.1$ and $n=0.5$ respectively.

Hydrogen-bonding: The pair correlations relevant to hydrogen bonding are shown in figure $3 \mathrm{~A}$ and 3B. In both $\mathrm{g}_{\mathrm{OwOw}}(\mathrm{r})$ and $\mathrm{g}_{\mathrm{OcOw}}(\mathrm{r})$, the first peak is observed at $\sim 2.7 \AA$ (figure $3 \mathrm{~A}$ and $3 \mathrm{~B})$, a characteristic $\mathrm{O}-\mathrm{O}$ distance in hydrogen-bonded systems, e.g. water ${ }^{38}$. However, in $\mathrm{g}_{\mathrm{OwH}}(\mathrm{r})$ only a small peak is observed at $\sim 1.8 \AA$ (figure $3 \mathrm{~B}$ ), the expected distance for a hydrogen bond, whereas $\mathrm{g}_{\mathrm{OcH}}(\mathrm{r})$ shows a large peak at $\sim 1.8 \AA$ (figure $3 \mathrm{~A}$ ), indicating that water-carbonate hydrogen bonding is preferred with respect to water-water hydrogen bonding. The CN distribution of $\mathrm{O}_{\mathrm{w}}$ in the first coordination sphere (figure 3C) shows a broad distribution with a mean $\mathrm{CN}$ of 4.1 for $\mathrm{O}_{\mathrm{w}}-\mathrm{O}_{\mathrm{w}}$, close to that of liquid water and of 7.3 for $\mathrm{O}_{\mathrm{w}^{-}}$ $\mathrm{O}_{\mathrm{c}}$ (table S3). However, the $\mathrm{CN}$ distribution of $\mathrm{H}-\mathrm{O}_{\mathrm{w}}$ hydrogen bonds shows that less than $20 \%$ of $\mathrm{H}$ atoms contribute to water-water hydrogen bonding (figure $3 \mathrm{D}$ ), while $63 \%$ of the $\mathrm{H}$ atoms contribute to water-carbonate hydrogen bonding. The $\mathrm{CN}$ of $\mathrm{O}_{\mathrm{w}}$ around $\mathrm{O}_{\mathrm{w}}$ is greatly reduced upon dehydration (Figure $3 \mathrm{C}$ ), with less than $10 \%$ of the remaining $\mathrm{H}$ atoms contributing to water-water hydrogen bonds. Although the mean $\mathrm{CN}$ of hydrogen bonded $\mathrm{H}$ to $\mathrm{O}_{\mathrm{c}}$ decreases by $41 \%$ (table S3), an increase is found in the relative number hydrogen binding to $\mathrm{O}_{\mathrm{c}}$ (from $63 \%$ to $78 \%$, figure $3 \mathrm{D}$ ). In total over $80 \%$ of the $\mathrm{H}$ are participating in hydrogen bonding, with all of the water molecules hydrogen bonded through at least one hydrogen to an oxygen. The angular distribution shows a broad peak at $175^{\circ}$ for both types of hydrogen bonds (Figure S5) and, additionally, a shoulder at $\sim 130^{\circ}$ in the $\mathrm{O}_{\mathrm{w}}-\mathrm{H}^{\cdots} \mathrm{O}_{\mathrm{w}}$ angular distribution.

Water percolation: To scrutinize the presence of water percolation, water molecules were counted as being in the same cluster either if the $\mathrm{O}_{\mathrm{w}}-\mathrm{O}_{\mathrm{w}}$ distance is smaller than $\mathrm{r}_{\text {cut }}$ (3.55-3.8 $\AA$ as defined by Bushuev et al. ${ }^{17}$ ) or if they are hydrogen bonded, either through $\mathrm{O}_{\mathrm{w}}{ }^{\cdots} \mathrm{H}$ or $\mathrm{O}_{\mathrm{c}}{ }^{\cdots} \mathrm{H}$ hydrogen bonds (figure S6). With this definition, percolation would result in clusters containing $\approx 220$ or $\approx 100$ water molecules for $n=1.1$ and $n=0.5$, respectively (i.e. almost all of the water molecules in the box). In the sample with $n=1.1$, indeed approximately $80-$ $90 \%$ of the water molecules $(\approx 220)$ are found in clusters, while no clusters with more than 40 molecules are found for the sample with $n=0.5$. However, if the water cluster is defined by hydrogen bonding between water molecules, no clusters with more than 25 molecules are found and for hydrogen bonding between water and carbonate ions no clusters with more than 50 molecules are found. This reveals that no long-range hydrogen bonded networks are present in either sample (figure S6). The identification of a water percolated structure, then, critically depends on the definition: samples with $n=1.1$ resides above the percolation if defined as in $^{17}$, but water molecules inside these clusters are only infrequently linked by hydrogen bonds between each other and, in this sense, we find no hydrogen-bonded water percolated structure in ACC. 

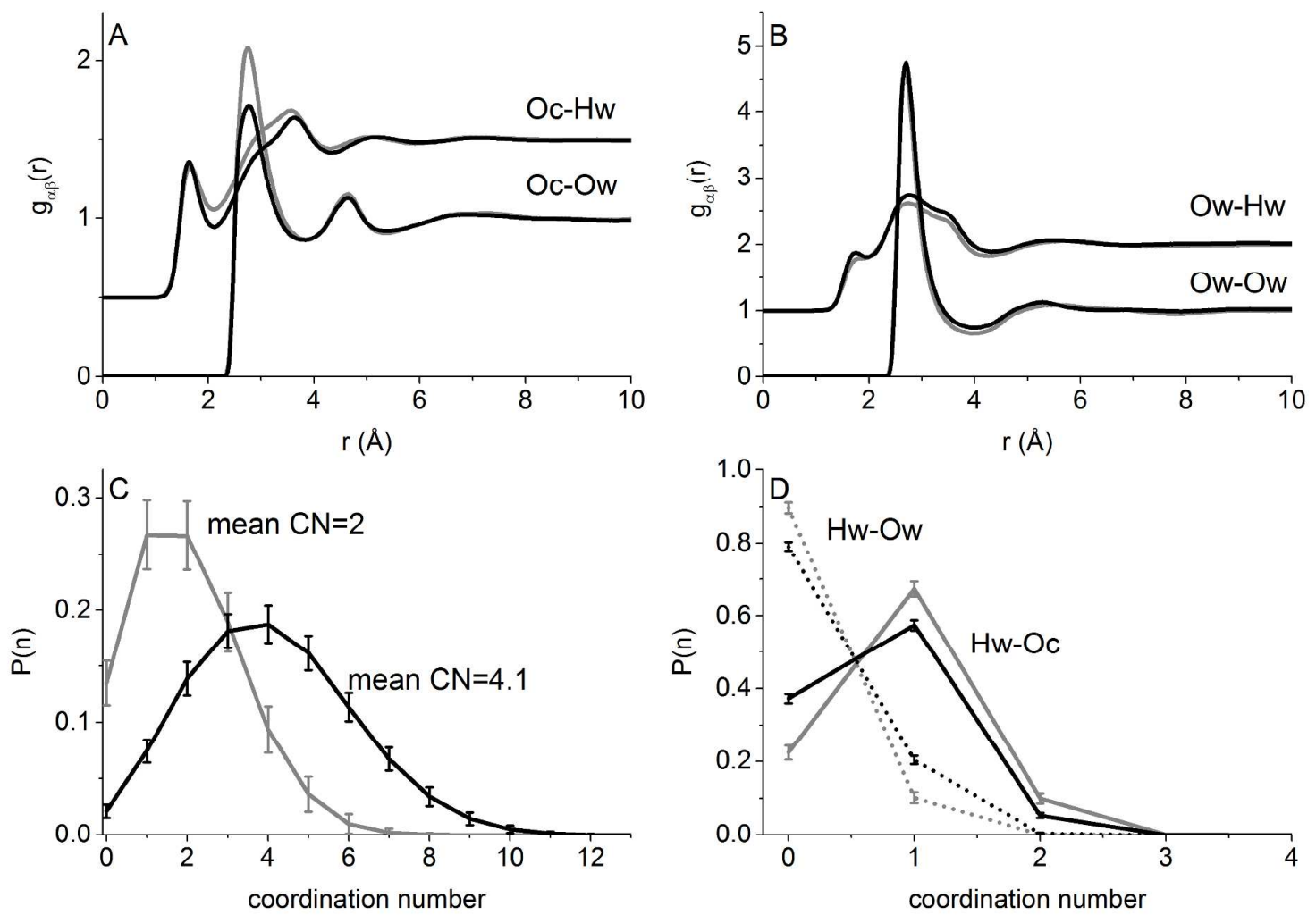

Figure 3. Selected inter-molecular ppdfs related to hydrogen bonding between carbonate and water (A) and between water molecules (B). The distribution in coordination numbers of $\mathrm{O}_{\mathrm{w}}$ around $\mathrm{O}_{\mathrm{w}}$ in the first coordination sphere from $2 \AA$ to $3.9 \AA(\mathrm{C})$ and of $\mathrm{O}$ around $\mathrm{H}$ in the $\mathrm{H}$ bond range (D). Black lines and grey lines represent data from $n=1.1$ and $n=0.5$ respectively

Vibrational spectroscopy: To substantiate the findings of the X-ray and neutron scattering work analyzed through the EPSR model, vibrational spectroscopy was used. Particular focus was put on the change in the carbonate environment and the interactions between water and the ions.

The vibrational modes of the carbonate and their changes with hydration were investigated with infrared (IR) and Raman spectroscopy (figure S7). The $v_{1}$ (symmetric stretch) and $v_{3}$ (asymmetric stretch) bands shift to higher frequencies upon dehydration (figure S7B and S7F) and the intensity of the $v_{2}$ (out-of-plane bending) band increases relative to the $v_{3}$ band (figure S7D), confirming a change in the local environment of the carbonate ions. On the $v_{1}$ band, a shoulder at $1050 \mathrm{~cm}^{-1}$ decreasing with dehydration is observed (figure S7E) while the splitting of the $v_{3}$ band increases at lower hydration levels (figure S7F). This band is sensitive to carbonate-related hydrogen bonding and an increase in the splitting indicates a decrease in hydrogen bonding ${ }^{39}$, in agreement with the $\mathrm{X}$-ray and neutron scattering results. The vibrational modes of water were compared to liquid water and to a saturated solution of $\mathrm{Na}_{2} \mathrm{CO}_{3}$. The broad $\mathrm{O}-\mathrm{H}$ stretch band at $3300 \mathrm{~cm}^{-1}$ of $\mathrm{H}_{2} \mathrm{O}$ in ACC samples and in the $\mathrm{Na}_{2} \mathrm{CO}_{3}$ solution show a longer tail towards the low frequency side compared to pure water, which is due to strong hydrogen bonding between carbonate ion and water ${ }^{40}$. 


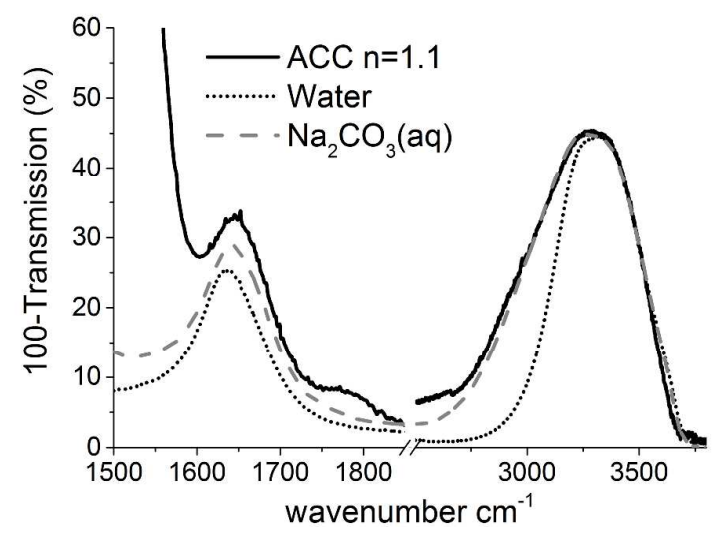

Figure 4. FTIR spectra of $\mathrm{ACC}, \mathrm{H}_{2} \mathrm{O}$ and a saturated $\mathrm{Na}_{2} \mathrm{CO}_{3}$ solution. Showing the water bending mode at $\sim 1650 \mathrm{~cm}^{-1}$ and the $\mathrm{O}-\mathrm{H}$ stretch mode at $\sim 3250 \mathrm{~cm}^{-1}$. The spectra have been rescaled to obtain comparative intensities in the $\mathrm{O}-\mathrm{H}$ stretch bands.

The vibrational modes at very low frequencies, measured by IINS (figure 5A), are assigned to vibrations of inter molecular bonds involving $\mathrm{H}$, in this case between water and the ions. The ACC spectra were compared to the spectra of several compounds available from the online TOSCA database. The spectra show two regions of interest; the translational region (20-400 $\left.\mathrm{cm}^{-1}\right)$ and the librational region $\left(400-1000 \mathrm{~cm}^{-1}\right)$. The edge at low wavenumbers of the librational bands is at $400 \mathrm{~cm}^{-1}$ typical of water binding to a single cation ${ }^{41}$, as expected from the total scattering analysis where $\sim 40 \%$ of the water molecules coordinate to one $\mathrm{Ca}$ (figure 2C). The translational band shows a sharp $\mathrm{Ca}-\mathrm{OH}_{2}$ stretch band at $85 \mathrm{~cm}^{-1}$, indicating that the $\mathrm{Ca}-\mathrm{OH}_{2}$ bond is weaker in $\mathrm{ACC}$ then in $\mathrm{MHC}$ where the $\mathrm{Ca}-\mathrm{OH}_{2}$ stretch is located at $157 \mathrm{~cm}^{-1}$ (figure 5B). The absence of a peak in the $200-400 \mathrm{~cm}^{-1}$ region rules out any large scale hydrogen bond network as found in both amorphous (e.g. low density amorphous ice ${ }^{42}$ ) or crystalline (e.g. MHC) compounds containing hydrogen bonded networks (figure 5B). The IINS spectra show considerable similarity to that of disordered water bound to the surface of a $\mathrm{PdO}$ catalyst ${ }^{43}$ and to that of water in amorphous calcium phosphate, in which local hydrogen bonding interactions exist but there is no extended hydrogen bonded network ${ }^{44}$.
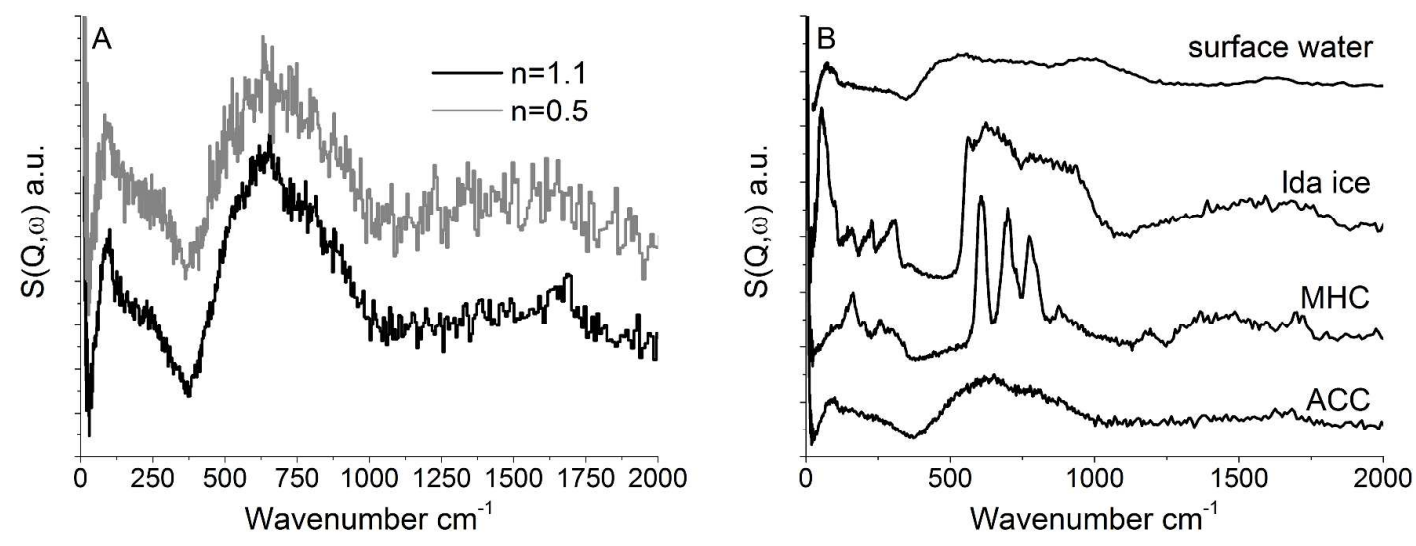
Figure 5. IINS spectra of ACC with $n=1.1$ and $n=0.5$ performed at $<30{ }^{\circ} \mathrm{K}$ (A) and comparison of ACC $(n=1.1)$, monohydrocalcite (MHC), low density amorphous ice (LDA ice) and water on a $\mathrm{PdO}$ catalyst (B).

\section{Discussion}

The Ca-O distances of $\sim 2.4 \AA$ similar to that found by previous $\mathrm{EXAFS}^{8,12,45-51}, \mathrm{NMR}^{22}$ and diffraction studies ${ }^{15-16}$ (see table S4). The mean coordination number reported in literature for both biogenic and synthetic ACC ranges from 4 to 8 , with most studies reporting values around $6-7$ (see table $\mathrm{S} 4$ ), with values for synthetic $\mathrm{ACC}^{8,15,18}$ close to the coordination number of 7.1 found in this study. However, the previous studies have focused on ACC with $\mathrm{n}=1$. The ppdfs (figure 2, 3 and S2) are also very similar to those reported by previous theoretical studies ${ }^{17,52-53}$, although the calculated densities are somewhat higher than what we report in this experimental study. Similar to Saharay et $\mathrm{al}^{53}$. we also find a preference for hydrogen bonding between water and carbonate, but we did not find any evidence for crystal like structures or change in the order of the system with dehydration. The decrease in the mean coordination number of $\mathrm{O}_{\mathrm{w}}$ and the concurrent increase in the $\mathrm{O}_{\mathrm{c}}$ coordination number around calcium, as well as the increased density of ACC upon dehydration suggest that the removal of water produces vacancies in the $\mathrm{Ca}$ coordination sphere that are being compensated for by the oxygen from carbonate ions. Interestingly the $\mathrm{Ca}-\mathrm{O}_{\text {tot }}$ coordination number remains unchanged. The increased bond distance of $\mathrm{O}_{\mathrm{c}}$ with increasing coordination number around $\mathrm{Ca}$ (figure S3) suggests that unlike water molecules, carbonate ions are sterically hindered in the first $\mathrm{Ca}-\mathrm{O}_{\mathrm{c}}$ coordination shell. The width of the $\mathrm{Ca}-\mathrm{O}_{\mathrm{c}} \mathrm{CN}$ distribution also shows that ACC may not be adequately described by models with only a single type of disordered $\mathrm{Ca}$ center as it has been previously attempted ${ }^{14,54}$. The angular distribution of $\mathrm{O}_{\mathrm{c}}$ around $\mathrm{Ca}$ only showed preferred angles below $100^{\circ}$ indicating that the angle between adjacent carbonates $\left(\mathrm{O}_{\mathrm{c}}\right)$ are close to $70^{\circ}$ in most of the calcium sites (figure $\mathrm{S} 4$ A). The lack of preferred angles above $100^{\circ}$ reflects that these angles are strongly dependent on the coordination number ${ }^{50-54}$ and is averaged out by the wide distribution of coordination numbers (figure $2 \mathrm{C}$ ).

The two preferred angles (figure S4) of $65^{\circ}$ and $140^{\circ}$ between $\mathrm{O}_{\mathrm{w}}$ binding to $\mathrm{Ca}$ are reminiscent of the values observed for the square antiprism coordination of the $\mathrm{Ca}$ ion in solution. The similarity also holds for the case of water molecules hydrogen bonded to carbonate ions, where the O-H stretch bands in the FTIR spectra of the ACC sample and that of the saturated $\mathrm{Na}_{2} \mathrm{CO}_{3}$ solution are very similar. This suggests an incomplete dehydration of the ions during ACC formation. Our model indicates that water is highly important to the structure of ACC as it adopts conformations that are comparable to the average structure of water interacting with ions in solution. Although the water in ACC are likely to be highly static, while water bound to ions in solution is highly labile ${ }^{55}$. No evidence was found for conformations close to those found in any of the crystalline compounds. This is in good agreement with ACC forming via spinodal decomposition ${ }^{56-58}$, where precipitation occurs instantly by instability of the solution and where dissolution/reprecipitation of ions is very limited. 
The analysis of the results obtained with the EPSR model showed that there are several binding sites for water were found in ACC. Hydrogen bonding occurs mainly between water molecules and carbonate ions and less frequently between different water molecules. However, all the water molecules were found to bind to at least one carbonate ion through at least one hydrogen bond. The water was also found to coordinate calcium with over $90 \%$ of the water molecules forming $\mathrm{H}_{2} \mathrm{O}-\mathrm{Ca}^{2+}$ coordination bonds. Since all the water molecules were found to have water-ion bond and most binding to both calcium and carbonate, the water can best be described as structural rather than a mixture of structural, mobile and liquid like as have been suggested by previous studies ${ }^{11,25}$. The different hydrogen bonding environments could explain the fact that NMR studies ${ }^{21,23,25}$, report multiple mobility's for hydrogen. However, the model presented here is purely structural, making dynamical considerations only possible at a speculative level. Moreover, our results suggest that the observation of different dehydration rates in ACC, as measured by TGA, is related to a gradual change in local structure upon dehydration rather than originating from an initial state with distinct water species ${ }^{25}$. This also implies that molecular rearrangement, at least to some extent, takes place at much lower temperature than the crystallization temperature.

\section{Conclusion}

We produced an atomistic model of ACC based on X-ray and neutron scattering data analyzed by the EPSR program. This model is in excellent agreement with analyses of vibrational spectroscopy data. Especially the IINS measurements that are exclusively sensitive to water molecules have provided key information to support the EPSR model. Herein, we described several structural features beyond that of the $\mathrm{Ca}-\mathrm{O}$ distance and average coordination number that have so far been available from literature. E.g. the ratio between bidentate $(20 \%)$ and monodentate $(80 \%)$ binding, fraction of hydrogens participation in hydrogen bonding with water $(\sim 10 \%)$ and carbonate $(\sim 70 \%)$, amount of water molecules interacting with carbonates(100\%) and $\mathrm{Ca}$ ions( $(90 \%)$. We found that the dehydration of ACC by heating results in a densification of the material and in a change of its local structure. This change is mainly associated to a rearrangement of the carbonate ions induced by the removal of water. While water percolation may exist, there is no evidence for long-range hydrogen bonded networks. We also find that the local structure of ACC studied here is related to the structure of the ions in solution prior to precipitation, which seems to support recent observations suggesting that ACC forms by rapid precipitation in unstable solutions. Although, to better understand the formation of ACC, a more detailed structural understanding of the ions in solution is likely needed, our results provide detailed insight into the structure of ACC and how dehydration leads to reorientation of the ions far below the crystallization temperature.

\section{Materials and methods}

The samples were prepared according to a protocol developed in our laboratory (for detail, see supplementary information) and extensively tested ${ }^{30,56}$. The samples were measured with FTIR and Raman spectroscopies, incoherent inelastic neutron scattering (IINS) at the TOSCA instrument $^{59}$, with neutron total scattering on the SANDALS instrument ${ }^{60}$ at ISIS (Oxford, 
UK) and X-ray total scattering on ID11 at the ESRF (Grenoble, France). Data reduction for both X-ray and neutron data was performed using the Gudrun software ${ }^{61}$. The pair distribution function (pdf) analysis was performed using the EPSR method ${ }^{27,62}$ using EPSR25. For the EPSR analysis a starting model was produced by placing $200 \mathrm{Ca}^{2+}, 200 \mathrm{CO}_{3}{ }^{2-}$ and either 220 or 100 water molecules, for samples with $n=1.1$ and $n=0.5$ respectively, in a cubic box. The box size was chosen to reproduce the experimentally measured densities. The model was energy minimized using a reference potential based on a set of Lennard-Jones potentials and electrostatic interactions (see SI). The reference potential used here was based on the work of Cuong et al. ${ }^{63}\left(\mathrm{CO}_{3}{ }^{2-}\right.$ and $\mathrm{Ca}^{2+}$ potential) and a standard SPC/E potential(25) for water was adopted. An empirical potential is added to the reference potential to fit the structure to the experimental data. This potential is derived from the difference between the calculated and experimental structure factor in an iterative process until a stable potential is reached(the method is described in detail in Soper $2005^{27}$ and Soper $2010^{62}$ ). Partial pdfs were extracted from the simulated model for direct analysis of the individual interatomic atom pairs (figure 2, 3 and S2 in SI). The mean coordination numbers $(\mathrm{CN})$ of several coordination spheres were calculated (table S3). The distribution of CNs was calculated for all the coordination spheres mention in table S3, but are only shown for selected coordination spheres. In addition, the angular distribution around a given atom was calculated, given as the angle between two atoms bound to a central atom.

\section{Acknowledgements}

We are grateful for support from Prof. A. K. Soper and Dr. S. K. Callear for help with Gudrun and EPSR. We also gratefully acknowledge ISIS and ESRF for beam time. We would also like to thank Ms. Jeannette Steffens for help with the ICP measurements and Dr. Marie Alberic and Dr. Zhaoyong Zou for help with the X-ray pdf measurements. The research was funded by a German Research Foundation grant within the framework of the Deutsch-Israelische Projektkooperation DIP.

\section{Supplementary information}

Figure showing the example of TGA measurements used to determine the hydration level. Table given the hydration level based multiple TGA measurements. Table containing the input parameters used in the EPSR program. Figure showing the ppdf not presented in the main text. Table showing the mean coordination numbers for a range of coordination spheres. Figure showing the mean bonding distance for oxygen around calcium as a function of coordination number. Figure showing the angular distribution of oxygen around calcium. Figure showing the linearity of the hydrogen bonds. Figure showing the presence of water clusters in the model. Figure showing the FTIR spectra of the two ACC samples. Table summarizing previously reported structural parameters for ACC. 


\section{References}

1. Jensen, A. C. S.; Ibsen, C. J. S.; Sutherland, D.; Birkedal, H., Transparent Aggregates of Nanocrystalline Hydroxyapatite. Cryst. Growth \& Des. 2014, 14 (12), 6343-6349.

2. Oaki, Y.; Kajiyama, S.; Nishimura, T.; Imai, H.; Kato, T., Nanosegregated Amorphous Composites of Calcium Carbonate and an Organic Polymer. Adv. Mater. 2008, 20 (19), 36333637.

3. Addadi, L.; Raz, S.; Weiner, S., Taking Advantage of Disorder: Amorphous Calcium Carbonate and Its Roles in Biomineralization. Adv. Mater. 2003, 15 (12), 959-970.

4. Weiner, S.; Sagi, I.; Addadi, L., Choosing the Crystallization Path Less Traveled. Science 2005, 309 (5737), 1027-1028.

5. Schmidt, I.; Lee, K.; Zolotoyabko, E.; Werner, P.; Shim, T. S.; Oh, Y.-K.; Fratzl, P.; Wagermaier, W., Nanocrystalline Calcitic Lens Arrays Fabricated by Self-Assembly Followed by Amorphous-to-Crystalline Phase Transformation. ACS Nano 2014, 8 (9), 9233 9238.

6. Aizenberg, J.; Muller, D. A.; Grazul, J. L.; Hamann, D. R., Direct Fabrication of Large Micropatterned Single Crystals. Science 2003, 299 (5610), 1205-1208.

7. Weiner, S.; Levi-Kalisman, Y.; Raz, S.; Addadi, L., Biologically Formed Amorphous Calcium Carbonate. Connect. Tissue Res. 2003, 44 (1), 214-218.

8. Politi, Y.; Levi - Kalisman, Y.; Raz, S.; Wilt, F.; Addadi, L.; Weiner, S.; Sagi, I., Structural Characterization of the Transient Amorphous Calcium Carbonate Precursor Phase in Sea Urchin Embryos. Adv. Funct. Mater. 2006, 16 (10), 1289-1298.

9. Politi, Y.; Metzler, R. A.; Abrecht, M.; Gilbert, B.; Wilt, F. H.; Sagi, I.; Addadi, L.; Weiner, S.; Gilbert, P. U. P. A., Transformation mechanism of Amorphous Calcium Carbonate Into Calcite in the Sea Urchin Larval Spicule. PNAS 2008, 105 (45), 17362-17366. 10. Raz, S.; Hamilton, P. C.; Wilt, F. H.; Weiner, S.; Addadi, L., The Transient Phase of Amorphous Calcium Carbonate in Sea Urchin Larval Spicules: The Involvement of Proteins and Magnesium Ions in Its Formation and Stabilization. Adv. Funct. Mater. 2003, 13 (6), 480486.

11. Ihli, J.; Wong, W. C.; Noel, E. H.; Kim, Y.-Y.; Kulak, A. N.; Christenson, H. K.; Duer, M. J.; Meldrum, F. C., Dehydration and Crystallization of Amorphous Calcium Carbonate in Solution and in Air. Nat Commun 2014, 5, 3169.

12. Levi-Kalisman, Y.; Raz, S.; Weiner, S.; Addadi, L.; Sagi, I., Structural Differences Between Biogenic Amorphous Calcium Carbonate Phases Using X-ray Absorption Spectroscopy. Adv. Funct. Mater. 2002, 12 (1), 43-48.

13. Reeder, R. J.; Tang, Y.; Schmidt, M. P.; Kubista, L. M.; Cowan, D. F.; Phillips, B. L., Characterization of Structure in Biogenic Amorphous Calcium Carbonate: Pair Distribution Function and Nuclear Magnetic Resonance Studies of Lobster Gastrolith. Cryst. Growth \& Des. 2013, 13 (5), 1905-1914.

14. Rez, P.; Sinha, S.; Gal, A., Nanocrystallite Model for Amorphous Calcium Carbonate. J. Appl. Cryst. 2014, 47 (5), 1651-1657.

15. Cobourne, G.; Mountjoy, G.; Rodriguez-Blanco, J. D.; Benning, L. G.; Hannon, A. C.; Plaisier, J. R., Neutron and X-ray Diffraction and Empirical Potential Structure Refinement Modelling of Magnesium Stabilised Amorphous Calcium Carbonate. J. Non-Cryst. Solids 2014, 401, 154-158.

16. Goodwin, A. L.; Michel, F. M.; Phillips, B. L.; Keen, D. A.; Dove, M. T.; Reeder, R. J., Nanoporous Structure and Medium-Range Order in Synthetic Amorphous Calcium Carbonate. Chem. Mater 2010, 22 (10), 3197-3205.

17. Bushuev, Y. G.; Finney, A. R.; Rodger, P. M., Stability and Structure of Hydrated Amorphous Calcium Carbonate. Cryst. Growth \& Des. 2015, 15 (11), 5269-5279. 
18. Malini, R. I.; Bushuev, Y. G.; Hall, S. A.; Freeman, C. L.; Rodger, P. M.; Harding, J. H., Using Simulation to Understand the Structure and Properties of Hydrated Amorphous Calcium Carbonate. CrystEngComm 2016, 18 (1), 92-101.

19. Shir, I. B.; Kababya, S.; Schmidt, A., Molecular-Level Structure: Property Relationships in Biogenic Calcium Carbonates: The Unique Insights of Solid-State NMR Spectroscopy. Isr. J. Chem. 2014, 54 (1-2), 74-85.

20. Akiva-Tal, A.; Kababya, S.; Balazs, Y. S.; Glazer, L.; Berman, A.; Sagi, A.; Schmidt, A., In Situ Molecular NMR Picture of Bioavailable Calcium Stabilized as Amorphous CaCO3 Biomineral in Crayfish Gastroliths. PNAS 2011, 108 (36), 14763-14768.

21. Kababya, S.; Gal, A.; Kahil, K.; Weiner, S.; Addadi, L.; Schmidt, A., PhosphateWater Interplay Tunes Amorphous Calcium Carbonate Metastability: Spontaneous Phase Separation and Crystallization vs Stabilization Viewed by Solid State NMR. J. Am. Chem. Soc. 2015, 137 (2), 990-998.

22. Singer, J. W.; Yazaydin, A. Ö.; Kirkpatrick, R. J.; Bowers, G. M., Structure and Transformation of Amorphous Calcium Carbonate: A Solid-State 43Ca NMR and Computational Molecular Dynamics Investigation. Chem. Mater 2012, 24 (10), 1828-1836.

23. Nebel, H.; Neumann, M.; Mayer, C.; Epple, M., On the Structure of Amorphous Calcium Carbonate - A Detailed Study by Solid-State NMR Spectroscopy. Inorg. Chem. 2008, 47 (17), 7874-7879.

24. Michel, F. M.; MacDonald, J.; Feng, J.; Phillips, B. L.; Ehm, L.; Tarabrella, C.; Parise, J. B.; Reeder, R. J., Structural Characteristics of Synthetic Amorphous Calcium Carbonate. Chem. Mater 2008, 20 (14), 4720-4728.

25. Schmidt, M. P.; Ilott, A. J.; Phillips, B. L.; Reeder, R. J., Structural Changes upon Dehydration of Amorphous Calcium Carbonate. Cryst. Growth \& Des. 2014, 14 (3), 938-951.

26. Tobler, D. J.; Rodriguez-Blanco, J. D.; Sørensen, H. O.; Stipp, S. L. S.; Dideriksen, $\mathrm{K}$, Effect of $\mathrm{pH}$ on Amorphous Calcium Carbonate Structure and Transformation. Cryst. Growth \& Des. 2016, 16 (8), 4500-4508.

27. Soper, A. K., Partial Structure Factors From Disordered Materials Diffraction Data: An Approach Using Empirical Potential Structure Refinement. Phys. Rev. B 2005, 72 (10), 104204.

28. Soper, A. K., Tests of the Empirical Potential Structure Refinement Method and a New Method of Application to Neutron Diffraction Data on Water. Mol. Phys. 2001, 99 (17), 1503-1516.

29. Soper, A. K., Computer Simulation as a Tool for the Interpretation of Total Scattering Data from Glasses and Liquids. Mol. Simul. 2012, 38 (14-15), 1171-1185.

30. Zou, Z.; Bertinetti, L.; Politi, Y.; Jensen, A. C. S.; Weiner, S.; Addadi, L.; Fratzl, P.; Habraken, W. J. E. M., Opposite Particle Size Effect on Amorphous Calcium Carbonate Crystallization in Water and during Heating in Air. Chem. Mater 2015, 27 (12), 4237-4246.

31. Cartwright, J. H. E.; Checa, A. G.; Gale, J. D.; Gebauer, D.; Sainz-Díaz, C. I., Calcium Carbonate Polyamorphism and Its Role in Biomineralization: How Many Amorphous Calcium Carbonates Are There? Angew. Chem. Int. Ed. 2012, 51 (48), 11960-11970. 32. Hesse, K.; Küppers, H.; Suess, E., Refinement of the Structure of Ikaite, CaCO36H2O. Z. Kristallogr. Cryst. Mater. 1983, 163 (1-4), 227-232.

33. Swainson, I. P., The Structure of Monohydrocalcite and the Phase Composition of the Beachrock Deposits of Lake Butler and Lake Fellmongery, South Australia. Am. Mineral 2008, 93 (7), 1014-1018.

34. Kamhi, S., On the Structure of Vaterite CaCO3. Acta Cryst. 1963, 16 (8), 770-772.

35. Graf, D., Crystallographic Tables for the Rhombohedral Carbonates. Am. Mineral 1961, 46 (11-2), 1283-1316.

36. De Villiers, J. P. R., Crystal Structures of Aragonite, Strontianite and Witherite. Am. Mineral 1971, 56, 758-767. 
37. Bruni, F.; Imberti, S.; Mancinelli, R.; Ricci, M. A., Aqueous Solutions of Divalent Chlorides: Ions Hydration Shell and Water Structure. J. Chem. Phys. 2012, 136 (6), 064520.

38. Soper, A. K., The Radial Distribution Functions of Water and Ice from 220 to $673 \mathrm{~K}$ and at Pressures up to $400 \mathrm{MPa}$. Chem. Phys. 2000, 258 (2-3), 121-137.

39. Hiemstra, T.; Rahnemaie, R.; van Riemsdijk, W. H., Surface Complexation of Carbonate on Goethite: IR Spectroscopy, Structure and Charge Distribution. J. Colloid Interface Sci. 2004, 278 (2), 282-290.

40. Williams, D. F., I., Spectroscopic Method in Organic Chemistry. 6th ed.; McGraw Hill: 2008.

41. Line, C. M. B.; Kearley, G. J., An Inelastic Incoherent Neutron Scattering Study of Water in Small-pored Zeolites and Other Water-bearing Minerals. J. Chem. Phys. 2000, 112 (20), 9058-9067.

42. Li, J., Inelastic Neutron Scattering Studies of Hydrogen Bonding in Ices. J. Chem. Phys. 1996, 105 (16), 6733-6755.

43. Parker, S. F.; Refson, K.; Hannon, A. C.; Barney, E. R.; Robertson, S. J.; Albers, P., Characterization of Hydrous Palladium Oxide: Implications for Low-Temperature Carbon Monoxide Oxidation. J. Phys. Chem. C 2010, 114 (33), 14164-14172.

44. Mitchell, P. C. H.; Parker, S. F.; Simkiss, J.; Simmons, J.; Taylor, M. G., Hydrated Sites in Biogenic Amorphous Calcium Phosphates: An Infrared, Raman, and Inelastic Neutron Scattering Study. J. Inorg. Biochem. 1996, 62 (3), 183-197.

45. Neumann, M.; Epple, M., Monohydrocalcite and Its Relationship to Hydrated Amorphous Calcium Carbonate in Biominerals. Eur. J. Inorg. Chem. 2007, 2007 (14), 19531957.

46. Taylor, M. G.; Simkiss, K.; Greaves, G.; Okazaki, M.; Mann, S., An X-ray Absorption Spectroscopy Study of the Structure and Transformation of Amorphous Calcium Carbonate from Plant Cystoliths. Proc. Royal Soc. B 1993, 252 (1333), 75-80.

47. Becker, A.; Ziegler, A.; Epple, M., The Mineral Phase in the Cuticles of two Species of Crustacea Consists of Magnesium Calcite, Amorphous Calcium Carbonate, and Amorphous Calcium Phosphate. Dalton Trans. 2005, (10), 1814-1820.

48. Becker, A.; Bismayer, U.; Epple, M.; Fabritius, H.; Hasse, B.; Shi, J.; Ziegler, A., Structural Characterisation of X-ray Amorphous Calcium Carbonate (ACC) in Sternal Deposits of the Crustacea Porcellio Scaber. Dalton Trans. 2003, (4), 551-555.

49. Levi-Kalisman, Y.; Raz, S.; Weiner, S.; Addadi, L.; Sagi, I., X-Ray Absorption Spectroscopy Studies on the Structure of a Biogenic "Amorphous" Calcium Carbonate Phase. Dalton Trans. 2000, (21), 3977-3982.

50. Hasse, B.; Ehrenberg, H.; Marxen, J. C.; Becker, W.; Epple, M., Calcium Carbonate Modifications in the Mineralized Shell of the Freshwater Snail Biomphalaria Glabrata. Chem. Eur. J. 2000, 6 (20), 3679-3685.

51. Marxen, J. C.; Becker, W.; Finke, D.; Hasse, B.; Epple, M., Early Mineralization in Biomphalaria Glabrata: Microscopic and Structural results. J. Molluscan Stud. 2003, 69 (2), 113-121.

52. Saharay, M.; Kirkpatrick, R. J., Onset of Orientational Order in Amorphous Calcium Carbonate (ACC) upon Dehydration. Chem. Phys. Lett. 2014, 591 (0), 287-291.

53. Saharay, M.; Yazaydin, A. O.; Kirkpatrick, R. J., Dehydration-Induced Amorphous Phases of Calcium Carbonate. J. Phys. Chem. B 2013, 117 (12), 3328-3336.

54. Rez, P.; Blackwell, A., Ca L23 Spectrum in Amorphous and Crystalline Phases of Calcium Carbonate. J. Phys. Chem. B 2011, 115 (38), 11193-11198.

55. Kohagen, M.; Mason, P. E.; Jungwirth, P., Accurate Description of Calcium Solvation in Concentrated Aqueous Solutions. J. Phys. Chem. B 2014, 118 (28), 7902-7909. 
56. Zou, Z.; Habraken, W. J. E. M.; Bertinetti, L.; Politi, Y.; Gal, A.; Weiner, S.; Addadi, L.; Fratzl, P., On the Phase Diagram of Calcium Carbonate Solutions. Adv. Mater. Interfaces 2016, 4 (1), 1600076.

57. Faatz, M.; Gröhn, F.; Wegner, G., Amorphous Calcium Carbonate: Synthesis and Potential Intermediate in Biomineralization. Adv. Mater. 2004, 16 (12), 996-1000.

58. Wallace, A. F.; Hedges, L. O.; Fernandez-Martinez, A.; Raiteri, P.; Gale, J. D.;

Waychunas, G. A.; Whitelam, S.; Banfield, J. F.; De Yoreo, J. J., Microscopic Evidence for Liquid-Liquid Separation in Supersaturated CaCO3 Solutions. Science 2013, 341 (6148), 885 889.

59. Stewart, F. P.; Felix, F.-A.; Anibal, J. R.-C.; John, T.; Svemir, R.; Roberto, S. P.; Giuseppe, G.; Fernández, C. J., Recent and Future Developments on TOSCA at ISIS. J. Phys. Conf. Ser. 2014, 554 (1), 012003.

60. Benmore, C.; Soper, A. The SANDALS Manual. A Guide to Performing Experiments on the Small Angle Neutron Diffractometer for Amorphous and Liquid Samples at ISIS; Council for the Central Lab. of the Research Councils (CLRC): 1998.

61. Soper, A., Rutherford Appleton Laboratory Technical Report RAL-TR-2011-013 2011. 62. Soper, A. K., Network Structure and Concentration Fluctuations in a Series of Elemental, Binary, and Tertiary Liquids and Glasses. J. Phys. Condens Matter 2010, 22 (40), 404210.

63. Van Coung, P.; Kvamme, B.; Kuznetsova, T.; Jensen, B., The Impact of Short-Range Force Field Parameters and Temperature Effect on Selective Adsorption of Water and CO2 on Calcite. wseas: 2012; Vol. 1.

\section{Table of content}

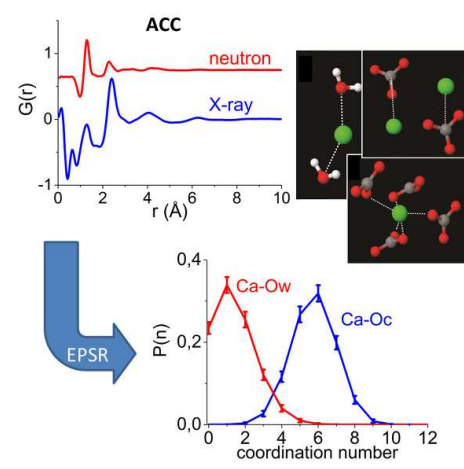




\section{Supporting information for:}

\section{Hydrogen Bonding in Amorphous Calcium Carbonate and Molecular Reorientation Induced by Dehydration}

Anders C. S. Jensen ${ }^{a}$, Silvia Imberti ${ }^{b}$, Stewart F. Parker ${ }^{b}$, Emanuel Schneck $^{a}$, Yael Politi ${ }^{a}$, Peter Fratzl $^{\mathrm{a}}$, Luca Bertinetti ${ }^{\mathrm{a}}$ and Wouter Habraken ${ }^{\mathrm{a}}$

[a] Max Planck Institute of Colloids and Interfaces, Potsdam-Golm Science Park, 14424

Potsdam, Germany

[b] STFC, Rutherford Appleton Laboratory, ISIS Neutron and Muon Source, Didcot, OX11

$$
\text { 0QX, UK }
$$

TGA results:
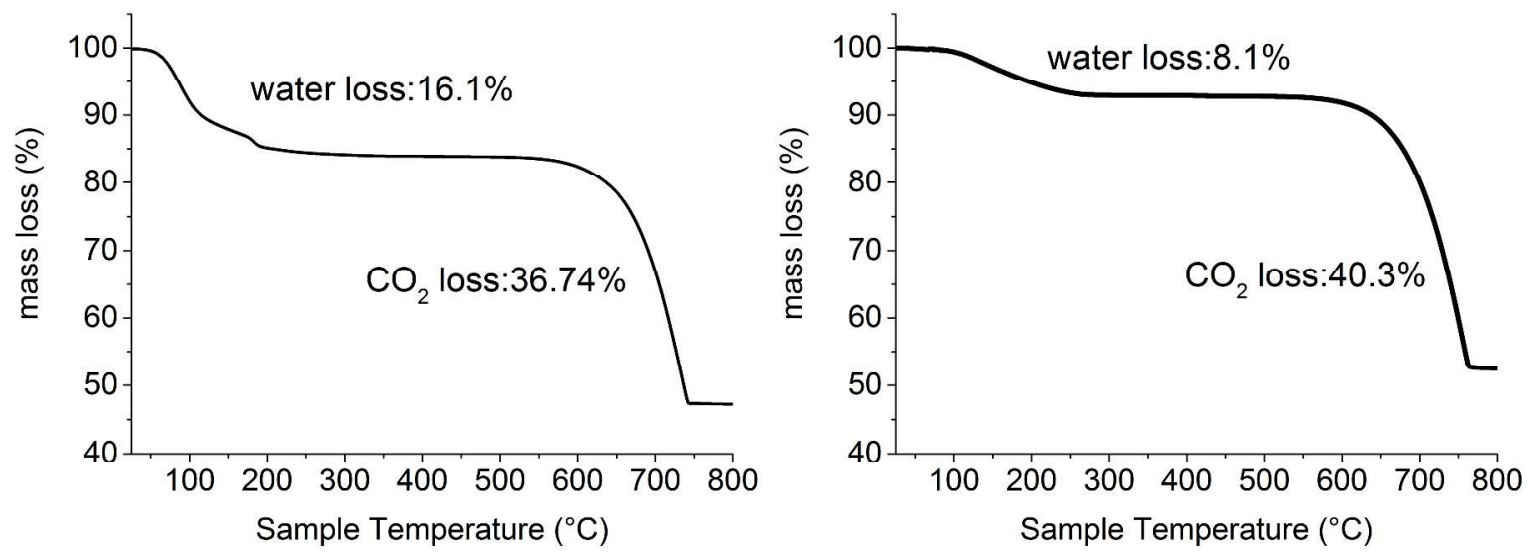

Figure S1: example of TGA data of ACC before (a) and after dehydration (b). 
Three determination of the hydration level was carried out and the mean is showed here

\begin{tabular}{|l|l|l|}
\hline & $\mathrm{H}_{2} \mathrm{O} / \mathrm{CaO}$ molar ratio & $\mathrm{CO}_{2} / \mathrm{CaO}$ molar ratio \\
\hline Before dehydration & $1.1+/-0.03$ & $0.99+/-0.01$ \\
\hline After dehydration & $0.5+/-0.05$ & $0.99+/-0.01$ \\
\hline
\end{tabular}

ICP showed that the $\mathrm{Na} / \mathrm{Ca}$ ratio was $\sim 2 \%$ slightly higher than expected from our previous work.

Particle size: The ACC particles were found to be $63.7+/-36.8 \mathrm{~nm}$, this is slightly smaller than that expected from our previous work.

\section{EPSR model:}

\section{Input parameters for EPSR}

Table S1: Reference potential for the EPSR model

\begin{tabular}{|l|c|c|c|}
\hline Atom & $\mathrm{E}[\mathrm{kJ} / \mathrm{mole}]$ & $\sigma[\AA]$ & Charge $[\mathrm{e}]$ \\
\hline $\mathrm{Ca}$ & 0.175 & 3.1 & 1.876 \\
\hline $\mathrm{O}$ & 0.1625 & 3.6 & -1.118 \\
\hline $\mathrm{C}$ & 0.5021 & 3.742 & 1.478 \\
\hline $\mathrm{O}_{\text {water }}$ & 0.65 & 3.166 & -0.8476 \\
\hline $\mathrm{H}_{\text {water }}$ & 0 & 0 & 0.4238 \\
\hline
\end{tabular}

Table S2: Box parameters for EPSR model

\begin{tabular}{|l|c|c|c|c|}
\hline CaCO3.nH2O & $\mathrm{N}_{\mathrm{Ca}}$ & $\mathrm{N}_{\text {Carbonate }}$ & $\mathrm{N}_{\text {water }}$ & Density $\left[\mathrm{g} / \mathrm{cm}^{2}\right]$ \\
\hline $\mathrm{n}=1.1$ & 200 & 200 & 220 & $2.282(2)$ \\
\hline
\end{tabular}




\begin{tabular}{|l|l|l|l|l|}
\hline $\mathrm{n}=0.5$ & 200 & 200 & 100 & $2.428(2)$ \\
\hline
\end{tabular}

\section{Model choice}

For each sample, two boxes were made: one with 200 formula units and one with 1000 formula units. The previous studies on ACC have used $\sim 1000$ formula units. However, this large model significantly slows the simulation so a smaller model was also made and no differences were observed between the two models. Therefore, the model with 200 formula units was used. The reference potential (Table S1) was compared against previous MD work on $\mathrm{ACC}^{1-2}$ and proved to be very similar. 

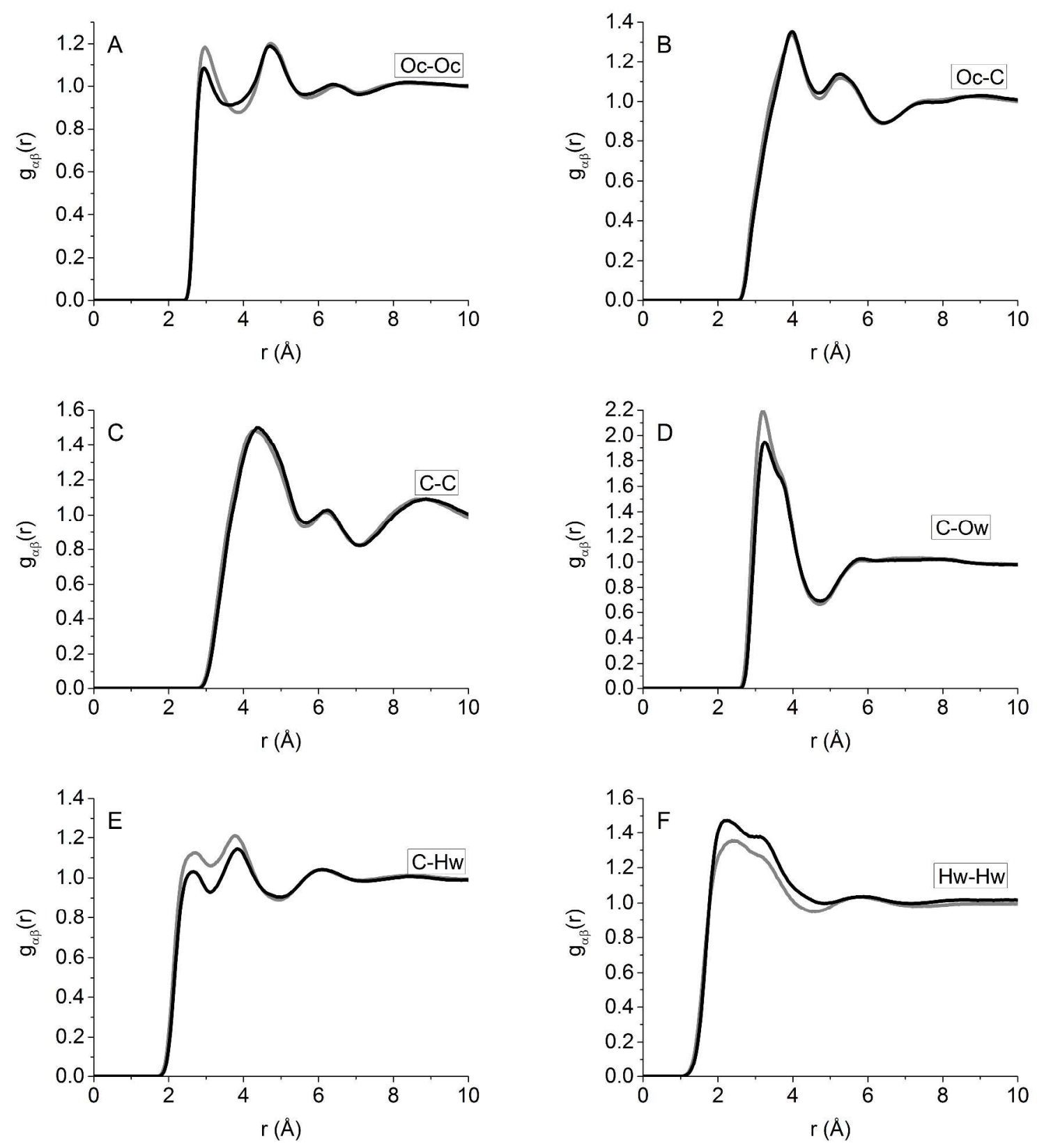

Figure S2: Partial pdf's extracted from the EPSR model, for $\mathrm{CaCO}_{3} \cdot \mathrm{nH}_{2} \mathrm{O}$ with $\mathrm{n}=1.1$ (black) and $\mathrm{n}=0.5$ (grey). 
Table S3: Coordination number of specific pair given as number of atom 2 around atom 1.

\begin{tabular}{|c|c|c|c|c|c|c|c|c|}
\hline Atom 1 & Atom 2 & $\mathbf{R}_{\min } \AA$ & $\mathbf{R}_{\max } \AA$ & $\begin{array}{c}\mathrm{CN} \\
\mathrm{n}=1.1\end{array}$ & $\begin{array}{c}\text { esd } \\
\mathrm{n}=1.1\end{array}$ & $\begin{array}{c}\mathrm{CN} \\
\mathrm{n}=0.5\end{array}$ & $\begin{array}{c}\text { esd } \\
n=0.5\end{array}$ & $\begin{array}{c}\text { Change } \\
\%\end{array}$ \\
\hline $\mathrm{Ca}$ & $\mathrm{Ca}$ & 2.5 & 5.1 & 5.7 & 1.5 & 6.8 & 1.3 & 19 \\
\hline $\mathrm{Ca}$ & $\mathrm{Ca}$ & 5.1 & 7.2 & 11.5 & 2.3 & 13.2 & 2.2 & 15 \\
\hline $\mathrm{Ca}$ & Ocarb & 2 & 3.1 & 5.8 & 1.2 & 6.3 & 1.1 & 10 \\
\hline Ocarb & $\mathrm{Ca}$ & 2 & 3.1 & 1.9 & 0.7 & 2.1 & 0.7 & 10 \\
\hline Ca & $\mathrm{C}$ & 2 & 3 & 1.1 & .9 & 1.2 & 0.9 & 8 \\
\hline C & $\mathrm{Ca}$ & 2 & 3 & 1.1 & .8 & 1.2 & 0.8 & 8 \\
\hline $\mathrm{Ca}$ & $\mathrm{C}$ & 3 & 4.1 & 3.7 & 1.3 & 4.1 & 1.4 & 12 \\
\hline C & $\mathrm{Ca}$ & 3 & 4.1 & 3.7 & 1.2 & 4.1 & 1.2 & 12 \\
\hline $\mathrm{Ca}$ & Owat & 2 & 3.2 & 1.4 & 1.1 & 0.9 & 0.9 & -40 \\
\hline Owat & $\mathrm{Ca}$ & 2 & 3.2 & 1.3 & 0.7 & 1.7 & 0.7 & 32 \\
\hline $\mathrm{Ca}$ & Hwat & 2 & 3.8 & 5.1 & 3 & 3.0 & 2.2 & -41 \\
\hline Hwat & $\mathrm{Ca}$ & 2 & 3.8 & 2.3 & 1.0 & 3.0 & 0.9 & 29 \\
\hline Ocarb & Owat & 2 & 3.9 & 2.7 & 1.7 & 1.5 & 1.2 & -41 \\
\hline Owat & Ocarb & 2 & 3.9 & 7.3 & 2.1 & 9.3 & 1.8 & 28 \\
\hline Ocarb & Hwat & 1.2 & 2.2 & 0.5 & 0.7 & 0.3 & 0.5 & -41 \\
\hline Hwat & Ocarb & 1.2 & 2.2 & 0.7 & 0.6 & 0.9 & 0.5 & 29 \\
\hline Owat & Owat & 2 & 3.9 & 4.1 & 2 & 2.0 & 1.5 & -51 \\
\hline Owat & Hwat & 1.2 & 2 & 0.4 & 0.6 & 0.2 & 0.5 & -51 \\
\hline Hwat & Owat & 1.2 & 2 & 0.2 & 0.4 & 0.1 & 0.3 & -51 \\
\hline
\end{tabular}




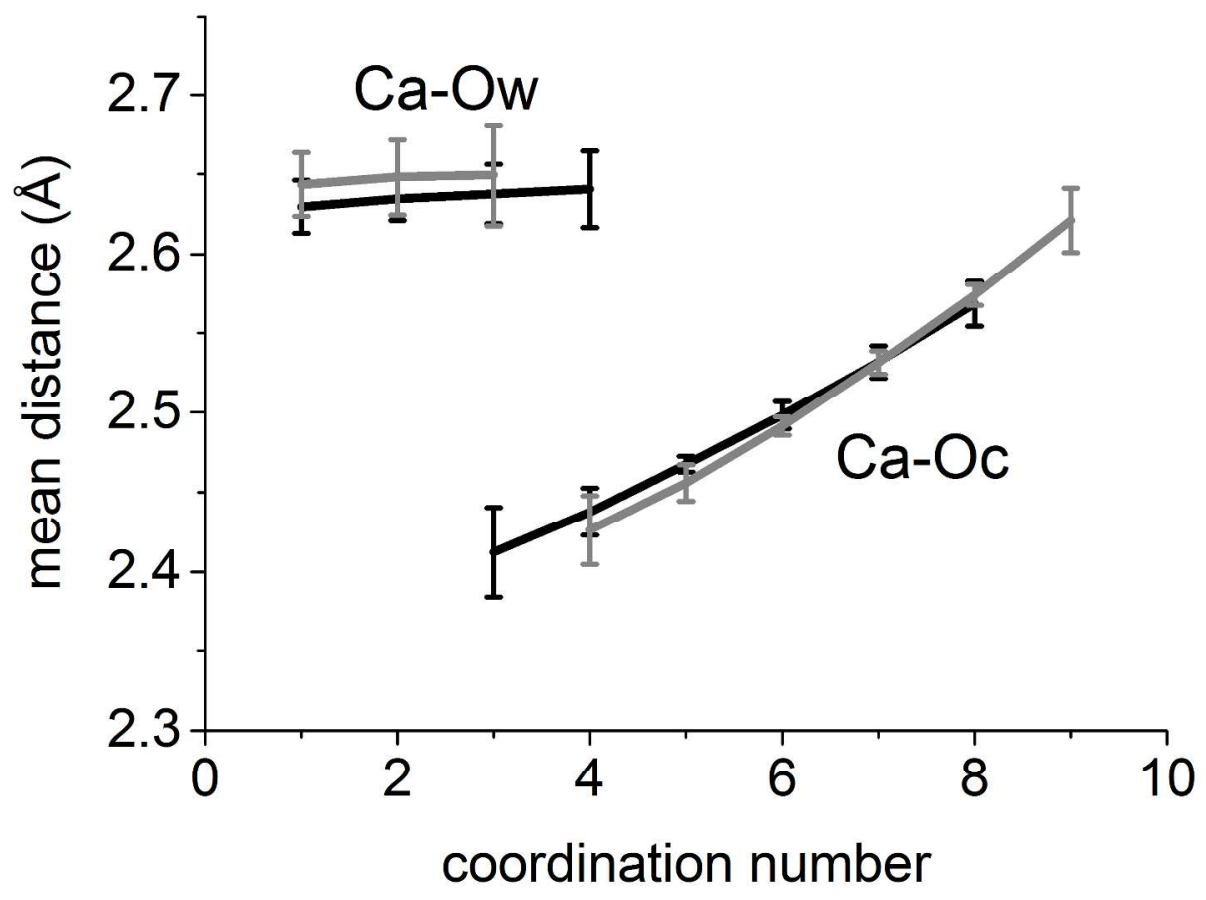

Figure S3: Mean binding distance as a function of coordination number for $\mathrm{O}$ binding to $\mathrm{Ca}$ in the first coordination sphere.
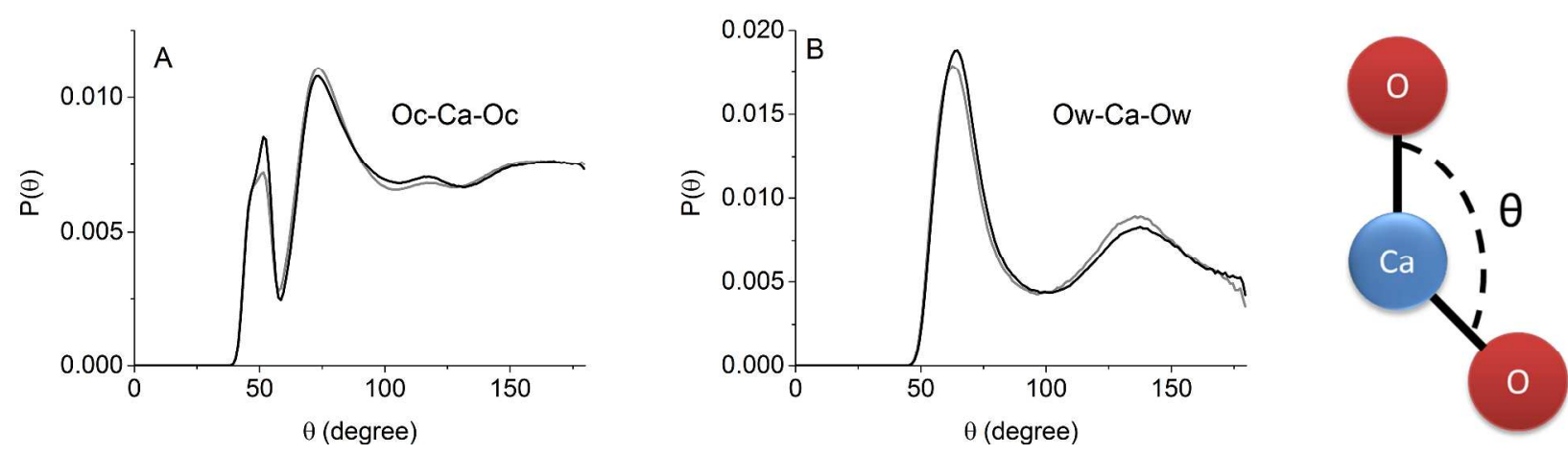

Figure S4: Angular distribution of oxygen binding to a central $\mathrm{Ca}$ in the first coordination sphere, given as the angle spanned by $\mathrm{O}-\mathrm{Ca}-\mathrm{O}$ (depicted on the far right). The sharp peak at $50^{\circ}$ in the Oc-Ca-Oc correlation originates from two oxygens from the same carbonate binding to $\mathrm{Ca}$, while two neighboring oxygens from separate carbonates give rise to the correlation at $75^{\circ}$. The 
angular distributions are calculated for both types of oxygen between $2 \AA$ and $3.1 \AA$ away from the calcium.
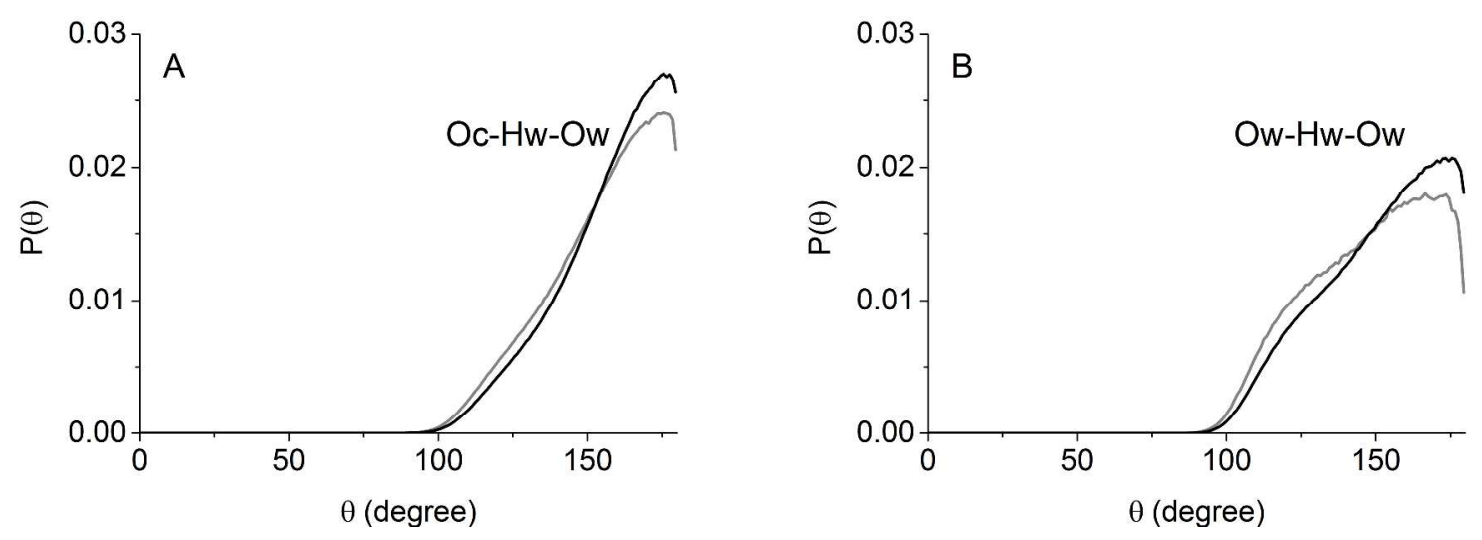

Figure S5: Angular distribution of the hydrogen bond between carbonate and water (left) and between water molecules (right), given as the angle spanned by $\mathrm{O}_{\mathrm{w}}-\mathrm{H}^{\cdots \cdots} \mathrm{O}$. 

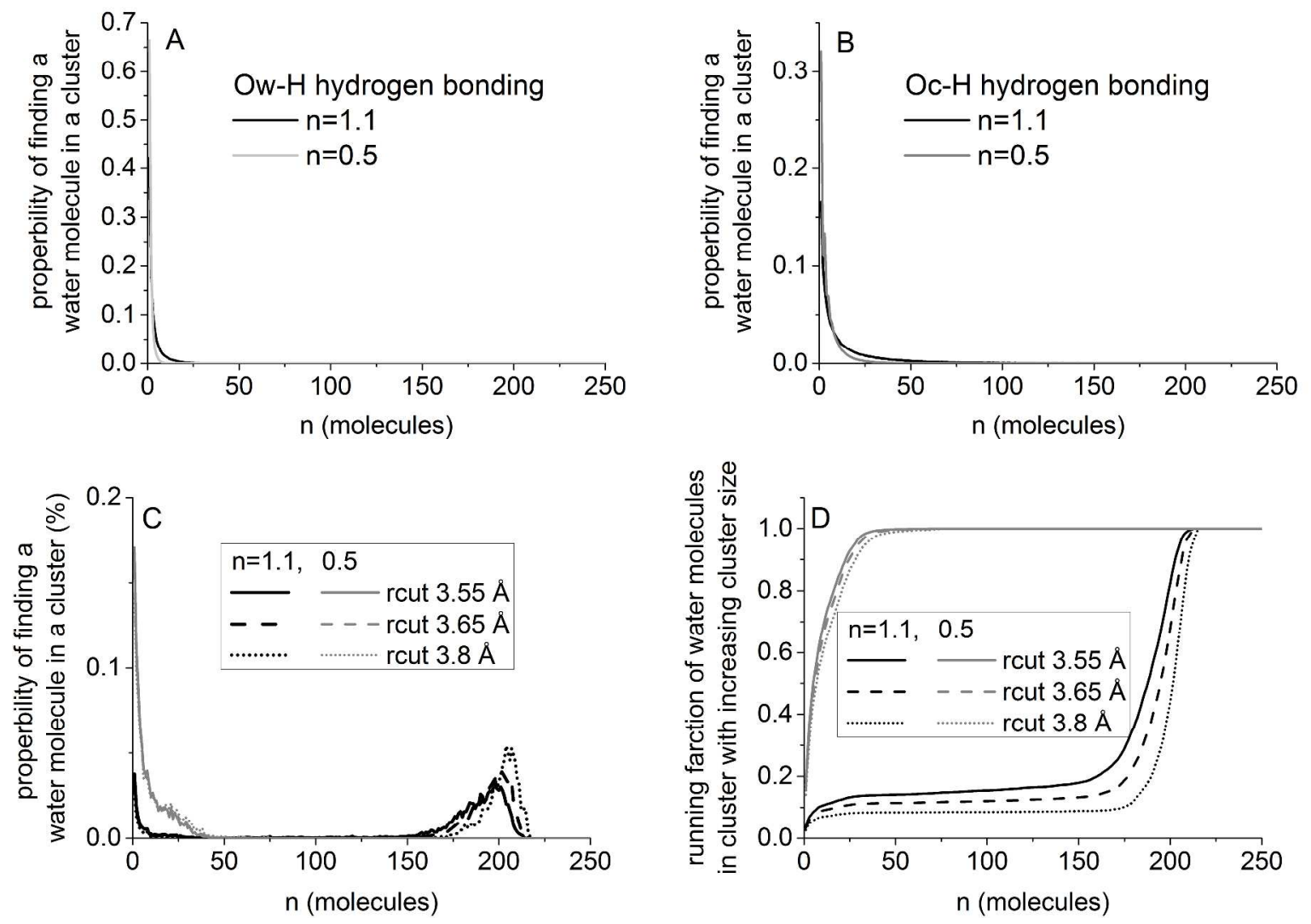

Figure S6: Cluster size distribution for the two ACC sample with $n=1.1$ and $n=0.5$ with water molecules considered to be in the same cluster if: A: water molecules share an H-bond B:water molecule share a $\mathrm{H}-$ bond with a carbonate $\mathrm{C}$ : $\mathrm{O}_{\mathrm{w}}$ are with rcut as given by Bushuev et al. The large population of clusters at 200 reflects that the box contains 220 water molecules and these clusters are in principle infinite, due to the periodic boundaries. D: running sum of water molecules in a cluster as a function of cluster size for C. 
A

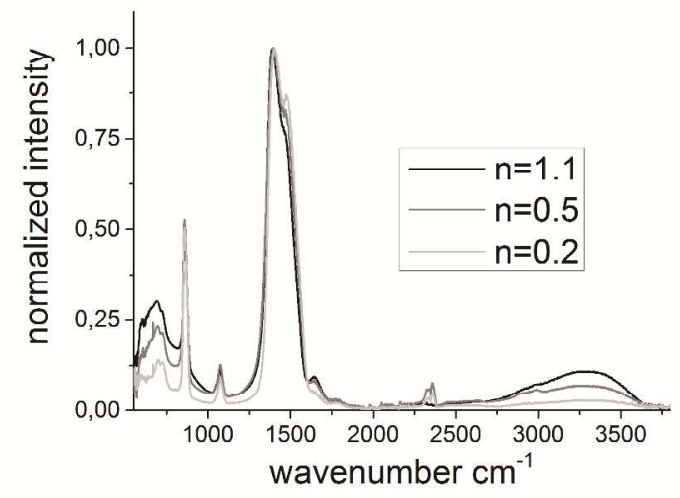

C

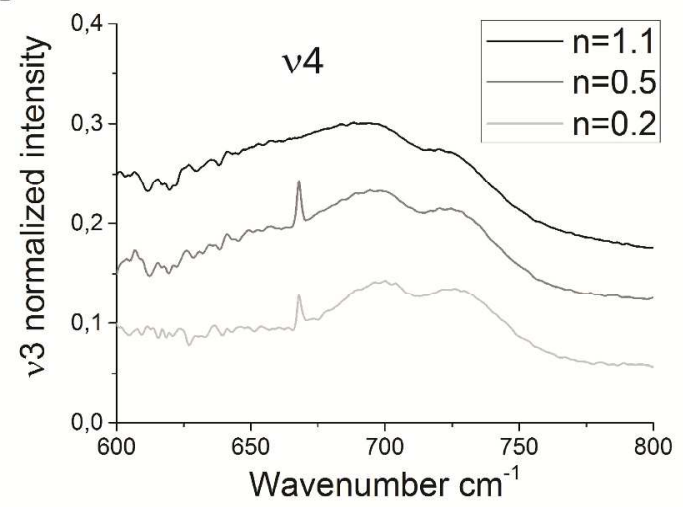

E

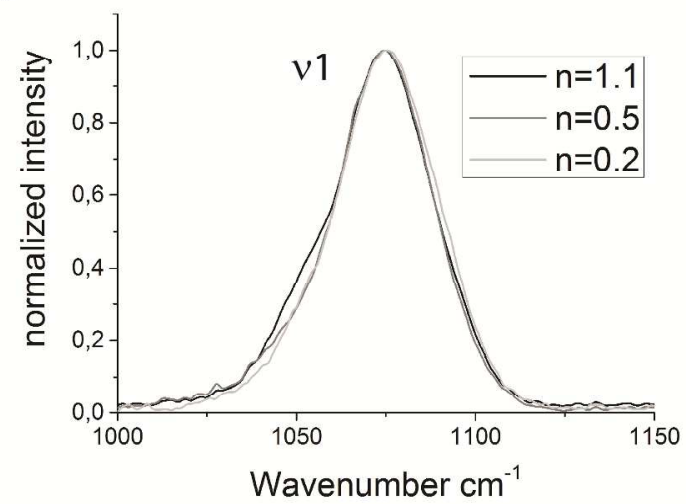

B

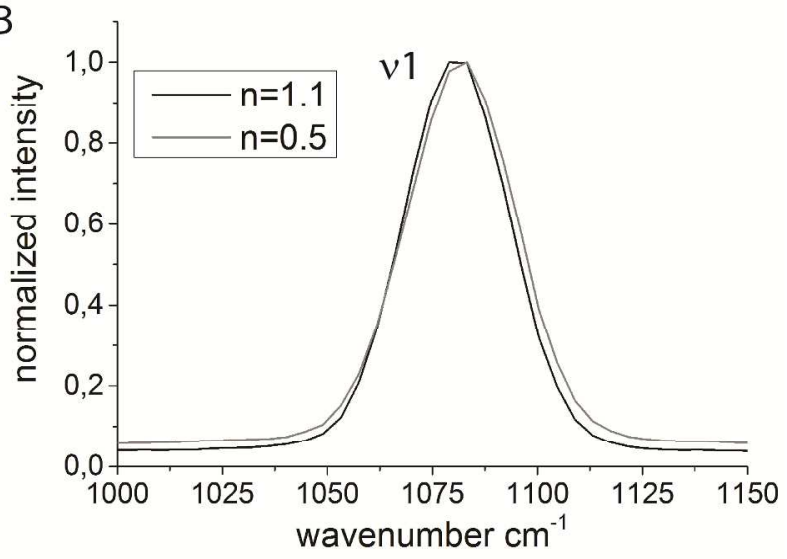

D

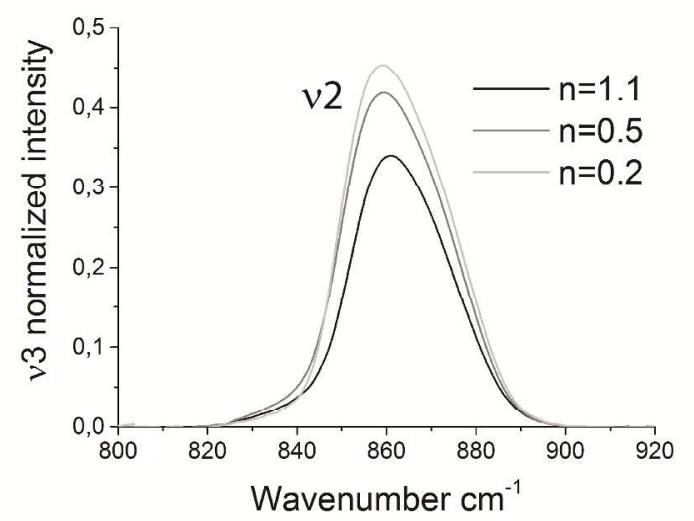

F

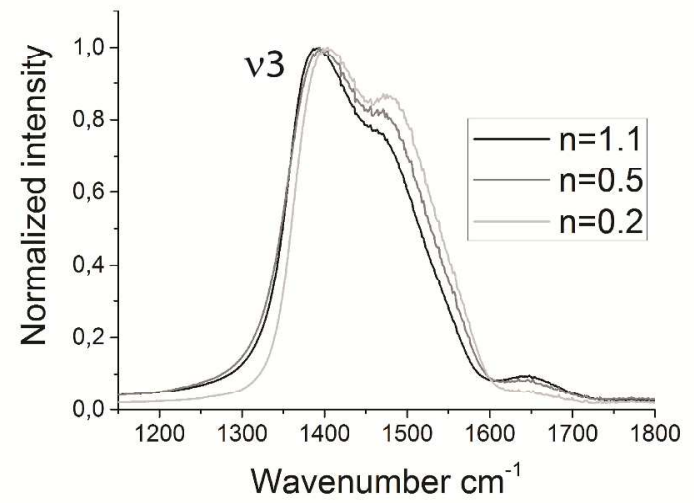

Figure S7: FTIR full spectra (A) with ACC at different hydration levels. A third hydration level was added for the FTIR analysis to emphasize the dependence on hydration level. The various vibrational modes of the carbonate are highlighted. $v 1$ measured with Raman (B) and FTIR (E), v2 normalized to the height of the $v 3$ peak (D), v4 normalized to the height of the $v 3$ peak $(\mathrm{C})$ and the $\mathrm{v} 3$ peak. 
Table S4: Coordination number and $\mathrm{Ca}-\mathrm{O}$ distance as determined by previous studies.

\begin{tabular}{|c|c|c|c|c|}
\hline ACC type & Technique & $\begin{array}{l}\text { Coordination } \\
\text { number }\end{array}$ & $\begin{array}{l}\mathrm{Ca}-\mathrm{O} \\
\text { diantance }\end{array}$ & Reference \\
\hline $\begin{array}{l}\text { Synthetic } \\
\mathrm{CaCO}_{3} * \mathrm{H}_{2} \mathrm{O}\end{array}$ & $\mathrm{xPdf}+\mathrm{RMC}$ & $5.6(1.5)$ & $2.4 \AA$ & Goodwin et al. $^{3}$ \\
\hline $\begin{array}{l}\text { Synthetic } \\
\mathrm{Ca}_{0.95} \mathrm{Mg}_{0.05} \mathrm{CO}_{3} * 0.25 \mathrm{H}_{2} \mathrm{O}\end{array}$ & $\begin{array}{l}\text { Xpdf }+ \text { npdf } \\
+ \text { EPSR }\end{array}$ & $6.7(1.7)$ & $2.41(0.02) \AA$ & Cobourne et al. ${ }^{4}$ \\
\hline $\begin{array}{l}\text { Theoretical } \\
\mathrm{ACC}_{\mathrm{RLJ}}: \mathrm{CaCO}_{3} * \mathrm{H}_{2} \mathrm{O} \\
\mathrm{ACC}_{\mathrm{RPm}}: \quad \mathrm{CaCO}_{3} * \mathrm{H}_{2} \mathrm{O} \\
\mathrm{ACC}_{\mathrm{MHC}}: \mathrm{CaCO}_{3} * \mathrm{H}_{2} \mathrm{O} \\
\mathrm{ACC}_{\mathrm{Ik}}: \quad \mathrm{CaCO}_{3} * \mathrm{H}_{2} \mathrm{O}\end{array}$ & $\begin{array}{l}\text { MD } \\
\text { simulation }\end{array}$ & $\begin{array}{l}7.64(0.01) \\
7.55(0.03) \\
7.63(0.02) \\
7.43(0.01)\end{array}$ & $\begin{array}{l}\sim 2.3 \AA \\
\sim 2.3 \AA \\
\sim 2.3 \AA \\
\sim 2.3 \AA\end{array}$ & Innocenti et al. ${ }^{5}$ \\
\hline $\begin{array}{l}\text { Biogenic } \\
\text { Lobster carapace } \\
\mathrm{CaCO}_{3}^{*} \mathrm{H}_{2} \mathrm{O} \\
\text { Plant cystholith } \\
\mathrm{CaCO}_{3}{ }^{*} \mathrm{H}_{2} \mathrm{O}\end{array}$ & EXAFS & $\begin{array}{l}\text { Lob. Cara. } \\
1.9(0.02) \AA \\
3.9(0.02) \AA \\
\text { Pla. Cys. } \\
\text { 2.3(0.02) } \AA \\
3.3(0.02) \AA\end{array}$ & $\begin{array}{l}\text { Lob. Cara } \\
2.23(0.01) \AA \\
2.41(0.01) \AA \\
\text { Pla. Cys. } \\
2.20(0.01) \AA \\
2.41(0.01) \AA\end{array}$ & $\begin{array}{l}\text { Levi-Kalisman } \\
\text { et al. }{ }^{6}\end{array}$ \\
\hline $\begin{array}{l}\text { Synthetic ACC } \\
\text { Biogenic* } \\
\text { P1(90\% ACC) } \\
\text { P2(70 \% ACC) } \\
\text { P3(90\% ACC) } \\
\text { P4(70 \% ACC) } \\
\text { P5(40\% ACC) } \\
\text { S48(70\% ACC) } \\
\text { S72(80\% ACC) }\end{array}$ & EXAFS & $\begin{array}{l}7(0.6) \\
6(0.2) \\
6(0.3) \\
6.2(0.7) \\
6(0.2) \\
6(0.6) \\
6(1) \\
6.2 \text { (fixed) }\end{array}$ & $\begin{array}{l}2.43(0.01) \AA \\
2.39(0.01) \AA \\
2.37(0.01) \AA \\
2.39(\text { fixed }) \AA \\
2.42(0.01) \AA \\
2.4(0.01) \AA \\
2.38(0.01) \AA \\
2.38(0.01) \AA \\
\end{array}$ & Politi et al. $^{7}$ \\
\hline $\begin{array}{l}\text { Biogenic } \\
\text { Plant cystolith }\end{array}$ & EXAFS & 8 & $2.35-2.73 \AA$ & Taylor et al. $^{8}$ \\
\hline $\begin{array}{l}\text { Biogenic } \\
\text { Porcellio scaber cuticula } \\
\text { Armadillidum vulgare cuticula }\end{array}$ & EXAFS & $\begin{array}{l}5.1 \\
6.6 \\
\end{array}$ & $\begin{array}{l}2.37 \AA \\
2.37 \AA \\
\end{array}$ & Becker et al. ${ }^{9}$ \\
\hline $\begin{array}{l}\text { Biogenic } \\
\text { Pyura Pachyderma tina spicules }\end{array}$ & EXAFS & 7.4 & $2.37 \AA$ & $\begin{array}{l}\text { Levi-Kalisman } \\
\text { et al. }{ }^{10}\end{array}$ \\
\hline $\begin{array}{l}\text { Biogenic } \\
\text { Porcellio scaber Sternal deposit }\end{array}$ & EXAFS & 3.8 & $2.38 \AA$ & Becker et al. $^{\text {"I }}$ \\
\hline $\begin{array}{l}\text { Biogenic } \\
\text { Biomphalaria glabrata Shell }\end{array}$ & EXAFS & 9 & 2.44 & Hasse et al. $^{12}$ \\
\hline $\begin{array}{l}\text { Biogenic } \\
\text { Biomphalaria glabrata Shell }\end{array}$ & EXAFS & 9 & 2.44 & Marxen et al. $^{13}$ \\
\hline
\end{tabular}

*biogenic samples in this study contained both ACC and calcite 
1. Bushuev, Y. G.; Finney, A. R.; Rodger, P. M., Stability and Structure of Hydrated Amorphous Calcium Carbonate. Cryst. Growth \& Des. 2015, 15, 5269-5279.

2. Raiteri, P.; Gale, J. D., Water Is the Key to Nonclassical Nucleation of Amorphous Calcium Carbonate. Journal of the American Chemical Society 2010, 132, 17623-17634.

3. Goodwin, A. L.; Michel, F. M.; Phillips, B. L.; Keen, D. A.; Dove, M. T.; Reeder, R. J., Nanoporous Structure and Medium-Range Order in Synthetic Amorphous Calcium Carbonate. Chem. Mater 2010, 22, 3197-3205.

4. Cobourne, G.; Mountjoy, G.; Rodriguez-Blanco, J. D.; Benning, L. G.; Hannon, A. C.; Plaisier, J. R., Neutron and X-Ray Diffraction and Empirical Potential Structure Refinement Modelling of Magnesium Stabilised Amorphous Calcium Carbonate. J. Non-Cryst. Solids 2014, 401, 154-158.

5. Malini, R. I.; Bushuev, Y. G.; Hall, S. A.; Freeman, C. L.; Rodger, P. M.; Harding, J. H., Using Simulation to Understand the Structure and Properties of Hydrated Amorphous Calcium Carbonate. CrystEngComm 2016, 18, 92-101.

6. Levi-Kalisman, Y.; Raz, S.; Weiner, S.; Addadi, L.; Sagi, I., Structural Differences between Biogenic Amorphous Calcium Carbonate Phases Using X-Ray Absorption Spectroscopy. Adv. Funct. Mater. 2002, 12, 43-48.

7. Politi, Y.; Levi-Kalisman, Y.; Raz, S.; Wilt, F.; Addadi, L.; Weiner, S.; Sagi, I., Structural Characterization of the Transient Amorphous Calcium Carbonate Precursor Phase in Sea Urchin Embryos. Adv. Funct. Mater. 2006, 16, 1289-1298.

8. Taylor, M. G.; Simkiss, K.; Greaves, G.; Okazaki, M.; Mann, S., An X-Ray Absorption Spectroscopy Study of the Structure and Transformation of Amorphous Calcium Carbonate from Plant Cystoliths. Proc. Royal Soc. B 1993, 252, 75-80.

9. Becker, A.; Ziegler, A.; Epple, M., The Mineral Phase in the Cuticles of Two Species of Crustacea Consists of Magnesium Calcite, Amorphous Calcium Carbonate, and Amorphous Calcium Phosphate. Dalton Trans. 2005, 1814-1820.

10. Levi-Kalisman, Y.; Raz, S.; Weiner, S.; Addadi, L.; Sagi, I., X-Ray Absorption Spectroscopy Studies on the Structure of a Biogenic "Amorphous" Calcium Carbonate Phase. Dalton Trans. 2000, 3977-3982.

11. Becker, A.; Bismayer, U.; Epple, M.; Fabritius, H.; Hasse, B.; Shi, J.; Ziegler, A., Structural Characterisation of X-Ray Amorphous Calcium Carbonate (Acc) in Sternal Deposits of the Crustacea Porcellio Scaber. Dalton Trans. 2003, 551-555.

12. Hasse, B.; Ehrenberg, H.; Marxen, J. C.; Becker, W.; Epple, M., Calcium Carbonate Modifications in the Mineralized Shell of the Freshwater Snail Biomphalaria Glabrata. Chem. Eur. J. 2000, 6, 3679-3685.

13. Marxen, J. C.; Becker, W.; Finke, D.; Hasse, B.; Epple, M., Early Mineralization in Biomphalaria Glabrata: Microscopic and Structural Results. J. Molluscan Stud. 2003, 69, 113121. 